\title{
Measuring sovereign risk spillovers and assessing the role of transmission channels: A spatial econometrics approach
}

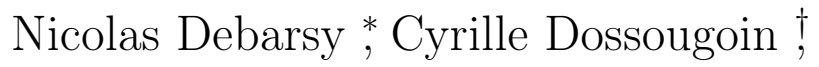 \\ Cem Ertur $;$ Jean-Yves Gnabo $§$
}

\begin{abstract}
We contribute to the literature on international risk spillovers by developing a unified framework based on spatial econometrics that enables us to address the following questions: (i) what are the effective transmission channels - real linkages and informational channels - of international risk spillovers across countries and/or regions, (ii) what are the most dominant ones, and (iii) which countries are most at risk for their environment and which are suffering the most from international exposure. Our analysis, based on 41 advanced and emerging economies from 2008Q1 to 2012Q4, shows that among the considered channels for explaining international spillovers of sovereign bond spreads, the informational channel is of utmost importance. Our results challenge previous findings from the literature in which the empirical strategy did not accommodate altogether important features of country spillovers, such as the co-existence of multiple transmission channels in the presence of contemporaneous and time-lagged interactions. Ultimately, our stress-testing analysis reveals important insights on countries prone either to international spillovers, international exposure or both at the regional and the worldwide level.
\end{abstract}

Key words: sovereign risk; transmission channels; spatial dynamic panel data; spillover analysis

JEL classifications: C33, C51, F34, F42

*Corresponding author. CNRS, LEO UMR CNRS 7322 F45067, Orléans, nicolas.debarsy@cnrs.fr

${ }^{\dagger}$ CORE \& LFIN, Université catholique de Louvain, cyrille.dossougoin@uclouvain.be. Cyrille Dossougoin is research fellow at the F.R.S - FNRS

${ }^{\ddagger}$ LEO UMR CNRS 7322, University of Orléans, cem.ertur@univ-orleans.fr

${ }^{\S}$ CeReFiM, University of Namur, jean-yves.gnabo@unamur.be 
Financial exposures across the continent are transmitting weakness and spreading fear from market to market, country to country, periphery to core. Christine Lagarde, Managing Director of IMF, Remarks at Jackson Hole, August 27, 2011.

Forewarned is forearmed. Understanding the dynamics of the international monetary system, its tipping points and edges, is a pre-requisite for effective management. Some progress has been made on this front. (...) The centrepiece of the IMF's surveillance efforts remain the country-specific Article IV consultations. Whether that country-specific focus, enshrined in the IMF's 1944 Articles, can be justified in today's highly integrated global financial network is a more open question. Andrew Haldane, October 29, 2014

\section{Introduction}

The increasing economic integration and interdependence of worldwide economies amid constant intensification of cross-border movement of goods, services, technologies and capital has been pivotal in explaining the macroeconomic and financial developments of emerging and industrialised economies over the past decades. As argued by Andrew Haldane, increased integration can be double-edged from a stability perspective. ${ }^{1}$ On one side, such integration improves the allocation of resources and acts as a shock absorber. On the other side, using the traditional analogy of the infectious disease, the more connected to others, the higher the chance of an agent being contaminated. In this case, connectivity stemming from the various economic and financial channels serves instead as a shock transmitter (for a formalisation of Haldane's (2014) conjecture, see Acemoglu et al. 2015). The so-called risk-sharing versus risk-spreading properties of the interconnectedness of economic agents has tended to materialise for international integration of economies into phases of sustained growth coupled with severe correcting episodes (see Rajan 2005 or Stulz 2007 on financial integration and large-scale financial crisis). Although it has been widely documented in the academic literature (see among others Bordo et al. 1999), the dramatic turmoil experienced in the past decade in many parts of the world reminds us that there is still much to learn about the implications of international integration for welfare gains and harm. ${ }^{2}$ It also supports the development

\footnotetext{
${ }^{1}$ Andrew Haldane was at the time Executive Director and Chief Economist of the Bank of England. The speech entitled "Managing global finance as a system" was made in October 2014 at the Birmingham University.

${ }^{2}$ Academic evidence has long pointed towards important spillover effects from national or international disturbances (Obstfeld \& Rogoff 1995, Forbes \& Warnock 2012, Fratzscher 2012, Grossman \&
} 
of new tools for macro-prudential surveillance of world economies to better calibrate the policy response. ${ }^{3}$

Against this background, this paper proposes to use an original empirical framework to address a set of important questions related to global economic integration in the quest for an improved understanding of the international transmission of sovereign risk and its monitoring. Specifically, we tackle the three following questions: (i) What are the channels of transmission for sovereign risk? (ii) Among the potential operating channels, what are the most important ones? (iii) In parallel with recent discussions on macro-prudential indicators for systemically important financial institutions, the socalled SiFIs, can we construct simple and flexible sovereign risk indicators for identifying and monitoring countries whose environments are most at risk and, conversely, those suffering the most from international exposure?

We document these questions empirically by using a large-scale database including 21 emerging and 20 advanced economies over the period 2008Q1-2012Q4. ${ }^{4}$ As is often the case in the literature (see among others Codogno et al. 2003, Beine et al. 2010, von Hagen et al. 2011, Favero \& Missale 2012), sovereign bond spread is taken as a measure of country-level risk and is explained in our regressions by traditional country-specific determinants, such as debt, inflation and current account as well as global factors. From a technical point of view, we rely on recent developments in spatial econometrics methods and apply a spatial dynamic panel data specification to characterise the role of international integration in the model.

The application of a spatial econometrics framework appears particularly well-suited for system-wide risk analysis in general. In our context, we can specifically emphasise the following features. First, as a general feature, it allows to explicitly account for interdependences across sovereigns by setting up an interaction matrix, which models the interdependences across sovereigns. Generally, this matrix is built upon observable economic variables providing clear economic interpretation. Eventually, its added value to the model can be assessed and formally tested through statistical testing. Second, our spatial econometric specification includes both contemporaneous and time-lagged crosscountry dependences. As such, it allows for a complete interpretation for risk analysis. Specifically, we can quantify, for any horizon, how much a change in macroeconomic and financial conditions in a specific country, such as an increase of its public debt, modifies the risk profile of other nations. Alternatively, we can address the reverse

\footnotetext{
Helpman 2014).

${ }^{3}$ See the above quote expressing the concern on this question of the Managing Director of the IMF, Christine Lagarde.

${ }^{4}$ We use the IMF classification of countries as defined in the World Economic Outlook report (April 2012) to assign each country in either group.
} 
question of how much a country may suffer from a change of economic conditions in other countries. The former mechanism can be related to the notion of "systemic risk" as developed in the literature on financial institutions and the latter to "systemic risk exposure" (Adrian \& Brunnermeier 2016, Acharya et al. 2017, Brownlees \& Engle 2017). To provide clearer policy implications, we analyse the impacts of the spatial model under two scenarios: (i) a standard unit change of the fundamental variable of interest (e.g. debt-to-GDP) for all countries, (ii) a modified version in which we account for heterogeneous changes in the explanatory variables across countries. As such, we can characterise what we later call the "real effect" or "bad neighbours effect" which might be more in line with the real world, the intuition being that a country is likely to be more at risk than others if for the same degree of integration, it is linked with economies that experience greater changes in their economic fundamentals (e.g. debt-to-GDP). Third, our approach enables us to feature single or multiple sources of interdependences (one or several interaction matrices) at the same time in the model. As such, we can pinpoint the relative role of a specific channel.

Compared to related studies, the contribution of our paper is fivefold. First, by relying on a maximum likelihood approach, we obtain unbiased and consistent estimates of the country-specific and system-wide determinants of sovereign bond spread in the presence of cross-sectional dependencies. By contrast, related contributions such as De Gregorio \& Valdés (2001) and Hernández \& Valdés (2001) use ordinary least square estimation to estimate their spatial lag model, while these estimators are known to be biased and inconsistent (Ord 1975). Second, our model accommodates both timedelayed and contemporaneous spatial interdependences. This feature of the model contrasts with Favero (2013) Global Vector Autoregression (GVAR) approach which only allows time-delayed interdependences, meaning that a change in a country is not supposed to affect its environment during the same period of time. It also departs from De Gregorio \& Valdés (2001) as well as Hernández \& Valdés (2001) in which interactions are restricted to contemporaneous interactions. Also, while considering specific sources of dynamics in the intensity of interactions, Blasques et al. (2016) could not account for pure time-dependence and spatio-temporal dependence among sovereign risks. The dynamic nature of our model via a combination of time, space and spacetime dependence is important to characterise spatio-temporal propagation patterns. This feature is particularly relevant for macroprudential policy analysis, especially if the assessment is built upon heterogeneous changes in the macroeconomic and financial fundamentals, what we call the "bad neighbours effect". Third, our approach also departs from the recent contributions of Kamil Yilmaz, Frank Diebold and co-authors (see among others Diebold \& Yilmaz 2014, 2015, Bostanci \& Yilmaz 2015) who use statistical association of returns to measure the transmission of risk while remaining 
silent on the underlying driving economic factors. Conversely, we are able to pinpoint the underlying economic channels at the origin of the propagation patterns. Fourth, as in De Gregorio \& Valdés (2001), Hernández \& Valdés (2001) and Favero (2013), we include several sources of risk transmission in our model, but we rely on a different methodology which allows us to assess their relative importance. ${ }^{5}$ Fifth, we use a large sample composed of emerging and advanced economies while most contributions focus on one of the two groups. As such, we can analyse intra as well as inter-regional transmission effects.

The remainder of the paper is as follows. Section 2 reviews the literature most closely related to our study. Section 3 introduces the data. Section 4 develops the econometric methodology while section 5 presents the variables included in the model and discusses the empirical results. Section 6 concludes.

\section{Literature review}

In this section, we review two recent strands of the literature related to our analysis: (i) the literature on international spillovers and (ii) the one on systemic risk indicators. More general discussions on standard determinants of sovereign bond's spreads can be found in Appendix A.

\subsection{International spillovers}

First, our paper links to the literature on international integration and its implications for contagion and risk spillovers (see, among others Beirne \& Fratzscher 2013, Antonakakis \& Vergos 2013, Kohonen 2014, Broto \& Pérez-Quiros 2015, Kilponen et al. 2015). There has been continuous interest in the past two decades in the global transmission of risk with particular attention paid to the role of the different channels at play (e.g. Forbes \& Rigobon 2002, Karolyi 2003, Bae et al. 2003, Bekaert et al. 2005, Dungey et al. 2005). The standard set of channels considered in the literature is usually broken down into two main categories: real linkages channels and informational channels (King \& Wadhwani 1990, Masson 1998, Pritsker 2001, Cipriani et al. 2015). The former type arises from trade or financial relationships across countries. For instance, if a country is facing economic turbulences, its supply and demand for international goods and services are likely to be down-scaled, implying negative externalities on its trading patterns. According to this channel, the propagation mechanism that leads local turmoils to diffuse to the whole system depends on pairwise physical connexions between

\footnotetext{
${ }^{5}$ By contrast, Blasques et al. (2016), rely only on one transmission channel.
} 
countries. Empirical evidence on the subject supports the existence of real-linkage channels and their contribution to international risk spillovers being due to either trade (Eichengreen et al. 1996) or financial relationships (Kaminsky \& Reinhart 2000). The mechanism underlying the informational channel is different. It builds on the existence of imperfect information in financial markets. It further supposes that market participants can use the characteristics attached to one country for extracting a signal on those judged as similar. In accordance, if a country suffers from economic disruption, international investors reassess the risk attached to those sharing similar characteristics, such as debt structure or bureaucratic quality, and adjust their trading strategy accordingly, leading to a transmission of the risk from one place to another. A long standing debate within the academic literature regards the semantic used to analyse international transmission mechanisms with terms such as contagion, interdependence, interconnectedness or spillovers as having sometimes been defined differently across studies (see in particular the definition of contagion given in Forbes \& Rigobon (2001) or Kodres \& Pritsker (2002)). We do not elaborate on the different terminologies in this paper and simply refer to our core notions, namely international spillovers and international exposure, as the dependence between sovereign risks of different economies, our goal being to shed light on the economic channels underlying these transmission effects. More specifically, we use international spillovers to describe how a change in macroeconomic and financial fundamentals diffuses across time to its environment and international exposure as the inverse mechanism (i.e. spillovers from the environment to a specific country). ${ }^{6,7}$ These effects have substantially gained in importance in academic works over the recent years. In the following lines, we review selected streams of the literature that help better understand the consequences and the sources of spillover effects. We start with theoretical considerations reviewing a set of relevant frameworks for the analysis of spillovers and then move to econometric modelling.

Turning to economic theory, there exists a wide literature aiming at replicating observed co-movements in economic activity across countries. It goes from early works on real business cycles (RBC) models featuring trade-related frictions to decrease risksharing across countries and increase the cross-country correlation of output (see Baxter, 1995 for a review) to more recent micro-founded new open-economy macroeconomics (NOEM) models on which we propose to focus. Overall, Dynamic Stochastic General Equilibrium models (DSGE hereafter) are now established as the current standard in macroeconomic modelling, serving as a basis for routine projections as well as coun-

\footnotetext{
${ }^{6}$ Kireyev \& Leonidov (2015) define international spillovers as "the impact of macroeconomic changes, possibly following a policy action, in one country on other countries"

${ }^{7}$ As discussed in section 4 , the diffusion process we are looking at embeds both cross-country and time dimensions (i.e. it includes instantaneous as well as short, medium and long term horizon effects).
} 
terfactual exercises performed within central banks. It thus appears very natural that, after a first generation of models focused on frictions on price setting and labour markets stemming from the seminal contributions of Smets \& Wouters (2007) and Christiano et al. (2005), we now observe emerging attempts to extend traditional frameworks to two-country settings (Ghironi 2000, Lubik \& Schorfheide 2006, Rabanal \& Tuesta 2010, and more recently De Walque et al. 2017). Meanwhile, the global financial crisis having put into lights the central role played by the financial sphere into shock propagation towards and within the real economy, part of the recent DSGE literature has focused on frictions in financial markets (see among others Galí \& Monacelli 2005, Gertler \& Karadi 2011, Christiano et al. 2014). A smaller but promising strand of the literature has attempted to combine the two previous dimensions, i.e. two-country DSGE models with financial frictions, with however a focus that is not directly to quantify spillover effects, (see Faia 2007, Davis \& Presno 2014, Yao 2012). More recently, Justiniano \& Preston (2010) and Alpanda \& Aysun (2014) have provided dedicated studies to document co-movements in economic fluctuations and potential transmission channels within this open-DSGE family models. Although they constitute laudable efforts to document spillover effects in a rigorous micro-founded setting, these models still do not explicitly account for the potentially complex (and time-varying) cross-country linkages resulting into interdependencies between individual units/countries and observed economic co-movements since they usually rely on strong assumptions on either portfolio structure, exchange rate behaviour (Dedola et al. 2013, De Walque et al. 2017) or calibrated values. In a recent study, Georgiadis \& Jančokovà (2017) perform a stylized counterfactual Monte Carlo experiment allowing to document that by missing accurate embedding of cross-country financial spillover channels, a wide range of standard DSGE settings erroneously associated foreign monetary policy shocks to domestic ones.

As discussed in Gnabo \& Scholtes (2016), parallel to these developments in macrofinancial modelling, the notion that economic system interconnectedness can impair economic stability has opened up a research agenda seeking to apply tools from the network theory literature to study the threats to system-wide risk posed by the various types of economic interdependence. The network thinking approach as labeled by Albert-László Barabási offers a set of powerful tools and conceptual framework for evaluating complex interactions among entities be it countries, firms or individuals among others. It implies to focus on interactions at play between entities composing a (social) system rather than the individual properties of those entities. Well developed in sociology and psychology (see Blau 1974 or Burt 1981 to quote a few), it is only recently that those methods and models such as cascading models started being applied to the analysis of economic problems (see among others Jackson 2010 or Newman 2010). The exploitation of network data in empirical studies has been shown to 
allow both the identification of peer effects and the analysis of their structure when estimating relationships between economic or social outcomes (such as the propensity to consume drugs or school achievement) of interacting individuals (Bramoullé et al. 2009). Generally, the network impact on economic behavior is analysed by relying on specific characteristics either at macro level (such as the density of connections or the segregation patterns among nodes) or micro level (such as the frequency with which two friends of a given node are friends with each other or how specific nodes are positioned in a network). Network density for instance has been shown to impact the diffusion of knowledge (Singh 2005), products, or conflicts (König et al. 2017), but also the way economic shocks (Acemoglu et al. 2012) and financial contagion operate (see Elliott et al. 2014, Acemoglu et al. 2015, Allen \& Babus 2009, Gai \& Kapadia 2010). Regarding the micro perspective, centrality of nodes as well as local clustering patterns have been shown to influence educational achievements (Calvò-Armengol et al. 2009) or the adoption of a new technology (Centola 2011) among other examples. This line of research has been particularly fruitful over the recent years in the area of finance to study contagion mechanisms and systemic risk. In particular, network science framework offers simple graphical representation based on a set of nodes (representing any financial institution in principle but most commonly applied to banks) connected by edges, which can be interpreted as any form of financial interdependency (e.g. crossexposures, cross-lending, common holdings etc.). Among remarkable contributions, we can quote the Allen \& Gale (2000) pioneering work on the effect of network topologies on the resilience to systemic failure or Battiston et al. (2012) and Acemoglu et al. (2015) on threshold effects in the relationship between the network stability and financial shocks. Battiston et al. (2017) document more specifically a variety of mechanisms of distress propagation including so-called first-round effects (i.e. shock on external assets) as well as second-round effects (i.e. distress induced in the interbank network), and third-round effects induced by possible fire sales. For a complete review on economic and financial networks see Hüser (2015) or Kireyev \& Leonidov (2015).

Echoing the progress made on the theoretical side, there has been substantial advancements for documenting the existence of economic interactions and to quantify their impact from real data. Among the approach applied in the literature, we can more specifically quote the Vector Autoregression (VAR) approach and more recently the spatial econometrics approach. The former has been widely used in macroeconomics since the pioneering contributions of Sims (1980). It relies on the general principal that a variable is a linear function of its past lags and the past lags of other variables. The model embeds several interesting features that allow to assess cross-country economic spillovers such as the analysis of impulse response function which quantify how much a shock in one series such as the economic condition in one country diffuses to other 
series. ${ }^{8}$ As explained in further details in section 4 , spatial econometrics is a branch of econometrics which has percolated into the field of macroeconomics and finance more recently. Its main object is to accommodate cross-sectional dependencies among observations and to explicitly model interactions among observations. It is generally done by embedding an interaction matrix into the model. Here also the model displays several interesting features for the analysis of economic spillovers. One of them that contrasts with traditional VAR models is the ability to consider alternative interaction matrices and in turn to analyse the spillovers mechanisms stemming from different transmission channels. The GVAR approach developed by Pesaran et al. (2004) stands as a third alternative. In some senses, it borrows ingredients of the two previously mentioned approaches by adding an interaction matrix to the VAR framework.

As further developed in sections 4 and 5, our study contributes more closely to the empirical body of researches and can be more specifically compared to five studies modelling country risk spillovers with comparable objectives. De Gregorio \& Valdés (2001) as well as Hernández \& Valdés (2001) analyse the transmission of crises in emerging market countries. For this, they empirically test the contribution of various transmission channels by using a framework inspired by spatial econometrics. More recently Favero (2013) uses the GVAR approach to perform a very similar exercise on industrialised countries. In a series of studies, Diebold \& Yilmaz (2014, 2015) and Bostanci \& Yilmaz (2015) analyse different types of economic and financial interconnectedness across sovereigns. For this, they develop a measure of connectedness in a vector autoregressive (VAR) model using forecast error variance decompositions. Among the remarkable features of their work is the ability to reconstruct financial (spillover) network. Once financial entities are represented as nodes and spillovers between pairs as edges, it is possible to apply traditional tools from network science to assess for instance the centrality of a specific financial entity. As for traditional VAR approach, a limit of the Diebold and Yilmaz framework lies in the absence of information on the channel(s) driving the spillover effects. Finally, in a recent contribution, Blasques et al. (2016) explore spatial effects among a set of 8 Euro-area countries. Our study provides complementary evidence on this question by exploiting a larger set of countries combining both emerging market and industrialized countries. In this respect, we are able to analyse the spillovers from one block of countries to the other in addition to intra-block and worldwide spillovers. Also, we argue in Section 4 that our econometric methodology addresses a number of important issues that were put aside in the previous studies. In particular, our approach allows us to deal with potential bias stemming

\footnotetext{
${ }^{8}$ Instead of considering several series for a single country, Bostanci \& Yilmaz (2015) estimate a VAR system composed of one single characteristic for a set of countries. Then, each equation models the evolution of this characteristic for each country as a function of the other countries.
} 
from cross-sectional dependencies among observations and enables us to feature multiple sources of transmission across countries in a single model. Another interesting feature is that, in addition to accounting for time dependence, our specification also includes both contemporaneous and time-lagged interactions among countries. This feature is important to characterise system-wide propagation patterns. For instance, it allows us to measure how a specific country responds through time to a change in financial and macro-economic conditions in its environment. As such, we can directly derive from our estimates an easy and flexible indicator of international risk spillover that could be helpful for risk surveillance.

\subsection{Systemic risk indicators}

A second related strand of the literature lies in the fast-growing field of macro-prudential supervision and systemic risk. The macro-prudential perspective refers to a system-wide approach as opposed to the traditional micro-prudential perspective that concerns individual entities regardless of their environment. For a decade, policymakers, regulators, academics and practitioners have focused on reshaping regulation and design of methods for supervision of financial institutions in a way that would take into account the dramatic increase in interconnectedness. In practice, however, such a task has proved to be extremely difficult.

As recalled in a somewhat provocative way by Bisias et al. (2012), the truism "one cannot manage what we do not measure" is particularly compelling for financial stability for which no consensus emerged right after the crisis, either on a unique definition of systemic risk or on accepted metrics to measure it. As such, one of the central aspects regarding the recent regulatory reforms has included the development of measures aiming to quantify the relationship between individual institutions and the system viewed as the collection of individual entities. Among the most prominent measures or indicators of systemic risk that have been developed, one can quote the Systemic Expected Shortfall (Acharya et al. 2017), the SRISK (Brownlees \& Engle 2017) and the DeltaCoVAR (Adrian \& Brunnermeier 2016)..$^{9}$ Equipped with this information, regulatory

\footnotetext{
${ }^{9}$ Systemic Expected Shortfall (SES) indicator represents the downside risk of a single financial firm in the event of market turmoil. In the same vein, Brownlees \& Engle (2017) develop a systemic risk measure (called the SRISK) combining both correlation measures between firm development and the rest of the system along with balance sheet data. These two measures - SES and SRISK- can be seen as "top-down measures" in the sense that they aim to determine the impact of distress occurring at the level of the financial system on an individual financial institution. Conversely, the DeltaCoVAR measure of systemic risk proposed by Adrian \& Brunnermeier (2016) might be seen as a "bottom-up" measure of systemic risk in that it assesses the impact of distress at the level of a single financial institution and the transmission of the associated risks to the entire financial system.
} 
authorities such as the European Systemic Risk Board or the Financial Stability Oversight Council can closely monitor the most fragile or risky institutions and take ex-ante policy action, such as deciding to require certain institutions to hold more capital in return. They can also intervene ex-post with better-calibrated policy responses. While much has been done on this question for financial institutions, less attention has been given to sovereigns, although a trend towards increased integration is equally concerned with world economies in general. ${ }^{10}$ In this paper, we propose to contribute to the literature on macroprudential supervision by developing novel measures directly derived from our spatial econometric model. Such measures based on the diffusion impacts of either temporary or permanent changes in economic fundamentals enable the assessment and ranking of countries with respect (i) to their impact on world-economies (international risk spillover) or, as an alternative, (ii) to their fragility to changing conditions in the rest of the world (international exposure). Importantly, our approach is simple and flexible. We can, for instance, parameterise the horizon at which we want to analyse the transmission of risk (short-, medium- or long-term). We can also focus on one specific channel of transmission and compute the associated measures of international risk. Alternatively, we can perform the same exercise by considering the whole set of economic channels altogether. This feature seems important for designing policy action. For instance, the response of a country to high international exposure might not be the same if international spillovers stem from trade relationships or from socioeconomic similarities. Likewise, working at an aggregated level, that is constructing the indicator by featuring the contribution of all relevant channels altogether is important for obtaining an accurate and complete picture of international risk transmission. Having a framework accommodating both disaggregated (i.e. channel-by-channel) and aggregated approaches as we manage to propose appears, therefore, particularly convenient for crisis prevention and crisis management.

\footnotetext{
${ }^{10}$ We can quote Diebold \& Yilmaz $(2014,2015)$, Bostanci \& Yilmaz (2015) among the contributions aiming to deal with world economies connectedness. An interesting feature of their approach is that it provides a matrix of forecast error variance decompositions whose rows (resp. columns) depict how much a country impacts (is exposed to) its environment. Such an indicator is therefore very close to the one we propose in this paper, with the notable exception that theirs is agnostic on the economic drivers of such relationships, albeit as mentioned earlier in our approach we explicitly feature the economic channels and compare their relative contribution. Both approaches can therefore be viewed as complementary.
} 


\section{Data}

This section first describes the data used to measure the sovereign risk and then presents some stylised facts regarding sovereign bonds spreads.

\subsection{Country risk data}

One important concern of researchers keen to analyse sovereign risk is the actual measure of risk to consider. Three types of measures are commonly used in the literature, namely bond yield spread (BYS), credit default swap (CDS) and credit ratings. The latter is an indicator provided by rating agencies such as Standard and Poor's, Moody's or Fitch and is constructed as a categorical variable. While being available for a large set of countries, credit ratings suffer from serious drawbacks for empirical studies. In particular, they barely vary through time and as such give limited information, especially in a time series context. By contrast, BYS and CDS provide continuous values stemming from the aggregate supply and demand of market participants (i.e. marketbased measures). As such, they reflect real-time changes in investors' beliefs about the country of interest. Practically, both measures generally exhibit pronounced variability, even at a very high frequency. In this study, we follow the main body of the literature by considering the sovereign bond yields spreads. Using bonds instead of CDS is motivated by two main factors. First, the sovereign CDS market is smaller in terms of volume compared to its bond counterpart. Second, sovereign CDS premiums include a counterparty risk (i.e the risk that both the CDS seller and the debt issuer default), which is not present in the BYS and ultimately can be difficult to measure (Coudert \& Gex 2010). When analysing both advanced and emerging sovereign spreads, one needs to find a consistent measure of bonds yields. As is often done in the literature, we consider the 10-year bond yields on the secondary bond market available on Datastream database for advanced economies. The spread is subsequently computed as the difference between bond yields and the 10-year US treasury bond yield. For emerging economies, we follow Beirne \& Fratzscher (2013) and rely on the Emerging Market Bond Index Global (EMBIG). This measure is an index published by JP Morgan on a daily frequency and constructed as a weighted average of the spread between the premiums of a set of Eurobonds and Brady bonds issued by emerging countries and bonds with similar features issued by US. This measure is widely used in the literature on emerging markets sovereign bonds. We obtain the data on EMBIG from the Global Economic Monitor database available on the World Bank website.

Raw data on sovereign bond spreads are aggregated over a quarter to match the frequency of countries' macroeconomic and financial conditions. We prefer quarterly 
data over annual or bi-annual data to conduct our empirical analysis in order to avoid possible pollution of spillover effects by other events if we were considering lower frequencies. ${ }^{11}$ Overall, the sample consists of observations for 41 countries over 20 quarters. As a matter of comparison, the number of countries included in our database is larger than in most studies which generally focus on a limited set of emerging economies as in De Gregorio \& Valdés (2001) which consider 20 countries or alternatively on European economies as in Favero (2013) which includes 11 countries in his analysis or Blasques et al. (2016), who work on a panel of 8 countries. Table 1 contains the list of considered countries while Table 2 provides an overview of the data used.

\subsection{Stylized facts of sovereign bond spreads}

We now turn to the key features and stylised facts of our data, by discussing both the time series and the cross-sectional dimension of sovereign bond spreads.

Figure 1 displays the median value of sovereign bond spread over time for both advanced economies (on the left) and emerging market countries (on the right). The shaded areas represent the interquartile range. Its visual inspection reveals at least two interesting features. First, both markets evolve very closely in the early quarters of the sample, marked by an increase of sovereign bond spreads. This period corresponds to the burst of the financial crisis in the US. While displaying similar patterns, the magnitude of the response to the crisis is different in the two groups. Emerging market countries exhibit a peak at 550 basis points for only 100 for advanced economies. In the 2008Q2-2009Q2 period, spreads stabilised around 200 basis points in emerging market countries. By contrast, advanced economies exhibit a strong increase for upper quantiles amid the European debt crisis. A second noticeable feature for advanced countries in this period is the increase of heterogeneity among the spreads as illustrated by larger interquantile range that shifted from less than 50 basis points before the crisis to 250 .

\section{Methodology: A spatial econometrics approach}

We begin the section by presenting the model used to analyse the determinants of sovereign bond spreads and to assess the role of international spillovers. We also compare our approach with that adopted in a set of selected contributions interested in explicitly accounting for international spillovers in the modelling of sovereign spreads. We use the paper by Hazir et al. (2016) to propose a specification which incorporates

\footnotetext{
${ }^{11}$ However, due to data constraints, we cannot get higher frequency data than quarterly.
} 
a convex combination of interaction matrices. As such, we can assess whether one or several interaction matrices dominate the others. We then derive model interpretations and propose new measures of impacts, based on country specific variations of the determinants. The real-based impacts, as we call them, will help measure the international risk attached to each country in a more realistic way.

\subsection{Econometric specification}

The specification we consider belongs to the wide class of spatial econometrics models whose main purpose is to account for cross-sectional dependence between observations (for an introduction, see LeSage \& Pace 2009). The model to be estimated is presented in equation (1):

$$
y_{n t}=\gamma y_{n, t-1}+\lambda W_{n} y_{n t}+\rho W_{n} y_{n, t-1}+X_{n t} \beta+\mu_{n}+\varepsilon_{n t}, t=1, \ldots, T
$$

where $y_{n t}$ is the $n \times 1$ vector containing the sovereign spread for all $n$ countries in the sample at time $t, X_{n t}$ is a $n \times k$ matrix containing both country-specific determinants at period $t$ and global factors affecting sovereign spreads and $\beta$ the associated vector of unknown parameters to be estimated. Our model includes the vector $\mu_{n}$ which contains individual country effects. These effects are considered here as fixed to account for possible correlation with the explanatory variables. The vector of error term $\varepsilon_{n t}$ is assumed to be normally distributed, centered and with a variance $\sigma_{\varepsilon}^{2} I_{n}$. The matrix $W_{n}$ represents the interaction scheme between observations. It is composed of the terms $w_{i j}$, which models how country $i$ is affected by country $j$. By convention, $w_{i i}=0$. In our setting, the interaction scheme models a transmission channel through which sovereign risk can spill over from one country to another. We report the discussion on the interaction matrices used to section 5 . The variable $W_{n} y_{n t}$ models contemporaneous interactions while $W_{n} y_{n, t-1}$ captures time-lagged interactions between sovereign risks. Parameters $\lambda$ and $\rho$ measure the intensity of these contemporaneous and time-lagged interactions respectively. Setting $\rho=\lambda=0$ leads to the traditional modelling approach of sovereign bond spreads as in Giordano et al. (2013).

If one of the two aforementioned parameters $(\rho$ and $\lambda)$ is statistically different from zero, we face evidence of transmission of risk across countries.

Anselin et al. (2008) refer to model (1) as the time-space dynamic model while Yu et al. (2008) label this model spatial dynamic panel data (SDPD) model. Yu et al. (2008) further discuss its theoretical properties and develop the associated quasi-maximum likelihood estimator. This model is well suited for our analysis since it captures both the persistence in bond spreads and the cross-sectional dependence between them. 
We would also like to compare our proposed framework with those already used in the literature to account for interactions in sovereign risks. In their respective contributions, De Gregorio \& Valdés (2001) and Hernández \& Valdés (2001) model transmission channels in the so-called Debt, Mexican and Asian crises for the former and in the Thai, Russian and Brazilian crises for the latter. Their specification shares similarities with those adopted in spatial econometrics, but do not fully address the econometric challenges caused by the modelling of simultaneous equations. Even though these two papers acknowledge the presence of the simultaneous equation problem, which implies biased and inconsistent least squares (LS) estimators, they nevertheless estimate their specification by LS, according to the argument that under the null of no transmission, the associated coefficient for transmission's intensity is not biased. However, as soon as one wishes to estimate transmission's intensity, one needs to rely on alternative estimation procedures, like (quasi-) maximum likelihood, two- stage least squares or a generalised method of moments (see Anselin 1988, Kelejian \& Prucha 1998, Anselin \& Bera 1998, Lee 2004). In this contribution, we explicitly account for this simultaneity by relying on quasi-maximum likelihood estimation.

Favero (2013) uses a modified global GVAR specification that accounts for time and space-time interdependence between government bond spreads in the euro area. However, his specification does not include contemporaneous interdependence as the conditions developed in Pesaran et al. (2004) to guarantee its weak exogeneity are not met. These conditions requires the number of individuals to be large, and the weights of the interaction matrix to be of order $1 / n$, such that the sum of their squares converges to 0 . As such, each economy can be viewed as a small open economy. In our contribution, we model the contemporaneous interdependence by relying on quasi-maximum likelihood estimation, a procedure which accounts for the endogeneity problem raised by the simultaneity across sovereign risks.

Finally, in a recent contribution, Blasques et al. (2016) rely on spatial econometrics tools to document the role of contagion among 8 European countries during the Eurozone debt crisis. For this, they develop an elegant static spatial panel data model that accommodates time-varying interactions between sovereigns. However, as it stands, their model cannot account for features that are potentially important for the modelling risk's propagation, such as pure time-dependence and spatio-temporal dependence, (i.e. $\gamma$ and $\rho$ in specification (1) are set to 0$)$.

\subsection{Convex combination of interaction matrices}

In addition to estimate model (1) for each interaction matrix separately and assessing the relevance of their information content to model interactions between countries, we 
are also interested in combining the information content of all considered transmission channels in a global interaction scheme which would aggregate all facets of interactions (each one being modelled by an interaction matrix) in the most relevant way.

With the notable exception of Blasques et al. (2016), the aforementioned studies include one or several regressions in which interaction matrices are set in competition in a single model. For this, the baseline model is extended to accommodate additional matrices along with their corresponding spatial coefficients. Inspired by the spatial model of Hondroyiannis et al. (2010), Favero (2013) includes jointly two different matrices in his GVAR model. A similar strategy is followed by De Gregorio \& Valdés (2001) with a larger number of matrices. These extended specifications have the advantage of better reflecting the variety of channels that jointly concur to the diffusion of country-level risk. While this approach is appealing, Lee \& Yu (2014) have shown that the estimation of our specification by (quasi-) maximum likelihood is not tractable in the presence of multiple interaction matrices.

To circumvent this issue, we adapt the methodology proposed by Hazir et al. (2016) for the cross-sectional case to our specification. This approach consists in first constructing an interaction matrix $W^{*}$ from a convex combination of all the considered transmission channels. Expressions (2) to (4) present the construction of the convex combination using $Q$ as the number of matrices considered.

$$
W^{*}=\sum_{i=1}^{Q} \kappa_{i} W_{i}
$$

such that

$$
\begin{aligned}
& \sum_{i=1}^{Q} \kappa_{i}=1 \\
& 0 \leq \kappa_{i} \leq 1 \quad i=1, \cdots, Q
\end{aligned}
$$

In the second step, we consider a grid for each $\kappa_{i}$ satisfying the constraints (3) and (4) and compute the value of the log-likelihood function of the model for all possible combinations of interaction matrices. Lastly, we select the values of $\kappa_{i}, i=1, \cdots, Q$ which maximise the log-likelihood function.

\subsection{Model interpretation}

Computation of impacts of a determinant's change on the dependent variable relies on the reduced form of model (1), reproduced in expression (5), with $L$, the lag operator, 


$$
\begin{aligned}
& S_{n}(\lambda)=\left(I_{n}-\lambda W_{n}\right) \text { and } C_{n}(\gamma, \rho)=-\left(\gamma I_{n}+\rho W_{n}\right) \\
& \qquad y_{n t}=\left[S_{n}(\lambda)+C_{n}(\gamma, \rho) L\right]^{-1}\left[X_{n t} \beta+\mu_{n}+\varepsilon_{n t}\right] .
\end{aligned}
$$

One of the main contributions of spatial autoregressive models is to account for indirect impacts, namely the impact on country $j$ 's dependent variable due to a change in a country $i$ 's determinant. Quantification of these indirect effects is of the utmost importance for economic policy as it allows to distinguish the local effect of a policy (namely in the country where it is implemented) and the induced effects on all the other countries (of the sample). As such, we could for instance document the impact of a change in US monetary policy on the US and rest of the world outputs and inflation. In this application, indirect effects may reflect either the sovereign risk fragility of a country to change in other countries' determinants (this relates to international exposure) or impacts on the sovereign risks of other countries of a change in a specific country's determinants (international spillovers).

Impacts' computation and interpretation for our specification are derived by Debarsy et al. (2012) and are based on partial derivatives of the dependent variable with respect to the concerned exogenous determinant. Debarsy et al. (2012) distinguish between contemporaneous impacts, which examine the current response of the dependent variable to a change in one of its determinants from diffusion effects, or spatio-temporal effects, which assess the futures responses of the dependent variable due to a change in explanatory variables. Contemporaneous impacts of a change in the $k^{\text {th }}$ regressor are contained in the $(n \times n)$ matrix presented in $(6)$ :

$$
\Xi_{t}^{(k)}=\frac{\partial y_{n t}}{\partial x_{k, n t}^{\prime}}=S_{n}(\lambda)^{-1} I_{n} \beta_{k} .
$$

Impact matrices are generally full and not symmetrical regardless of the sparseness and structure of the interaction matrix $W_{n}$. These matrices are full due to the term $S_{n}(\lambda)^{-1}=I_{n}+\lambda W_{n}+\lambda^{2} W_{n}^{2}+\cdots$. Diagonal elements of this matrix, $\Xi_{i i, t}^{(k)}=\frac{\partial y_{i t}}{\partial x_{i t, k}}$, represent direct effects. These direct impacts are heterogeneous in the presence of spatial autocorrelation, due to feedback effects which capture the impact that first, second and higher order neighbouring countries will have on the country where the change initially occurred. This heterogeneity in direct impacts is called interactive heterogeneity by Debarsy \& Ertur (2010), in contrast with standard individual heterogeneity in panel data models.

As stated earlier, one important contribution of spatial autoregressive models is the modelling and quantification of indirect effects. These indirect effects are given by the off-diagonal elements of the impact matrix. Two different interpretations of these effects 
exist. First, we can analyse how a change in the determinant in a country will affect the dependent variable of all the other countries. We may interpret this analysis in terms of international spillovers, effects on the network or systemic risk if one studies financial data. For country $i$ and regressor $k$, this measure is constructed in expression (7):

$$
I S_{i}^{(k)}=\sum_{j \neq i}^{n} \frac{\partial y_{j t}}{\partial x_{i t}} .
$$

Alternatively, we may analyse how a country is sensitive to a change (of the same magnitude) in some determinant in all other countries. For financial data, this analysis may refer to international exposure. Expression (8) presents this measure for country $i$ and the $k^{\text {th }}$ variable.

$$
I E_{i}^{(k)}=\sum_{j \neq i}^{n} \frac{\partial y_{i t}}{\partial x_{j t}},
$$

Finally, for each observation, we can construct the total effect, which is the sum of direct and indirect effects.

To interpret these potential $n^{2}$ impacts, LeSage \& Pace (2009) propose three scalar summary results to simplify economic interpretations. They first derive the average direct effect (ADE), that is the average of the diagonal elements of the impact matrix, presented in expression (9) for variable $k$ :

$$
A D E^{(k)}=\frac{1}{n} \operatorname{tr}\left(\Xi_{t}^{(k)}\right)
$$

where $\operatorname{tr}($.$) stands for the trace operator. They also propose to compute the average of$ total indirect effects (AIE). Its expression for variable $k$ is shown in expression (10):

$$
A I E^{(k)}=\frac{1}{n} \iota_{n}^{\prime}\left(\Xi_{n t}^{(k)}-\operatorname{Diag}\left(\Xi_{t}^{(k)}\right)\right) \iota_{n},
$$

where $\iota_{n}$ is the unit column vector and $\operatorname{Diag}(A)$ is a diagonal matrix made of the diagonal elements of $A$. Finally, they derive the average total effect (ATE). For variable $k$, this summary measure is presented in expression (11):

$$
A T E^{(k)}=\frac{1}{n} \iota_{n}^{\prime}\left(\Xi_{t}^{(k)}\right) \iota_{n}
$$

Finally, we follow LeSage \& Pace (2009) to perform inference on these scalar summary values. We construct their distribution using a large number of simulated parameter 
values drawn from the multivariate normal distribution implied by the maximum likelihood estimator. ${ }^{12}$ We then estimate credible confidence intervals for each of the scalar effects.

In addition to contemporaneous impacts, Debarsy et al. (2012) develop spatiotemporal or diffusion effects, which measure the future response of the dependent variable due to a change in one of its determinants and distinguish between transitory and permanent changes. The former assumes that the determinant only varies at time $t$ and then goes back to its original level while the latter supposes a permanent shift starting in period $t$. Impacts of a transitory change in the $k^{\text {th }}$ variable on a $h$ periods ahead response are presented in equation (12) while impacts due to a permanent change $h$ periods ahead of the initial variation are presented in equation (13).

$$
\begin{gathered}
\Xi_{t+h, \text { trans }}^{(k)}=(-1)^{h}\left(S_{n}(\lambda)^{-1} C_{n}(\rho, \gamma)\right)^{h} S_{n}(\lambda)^{-1} I_{n} \beta_{k} \\
\Xi_{t+h, p e r m}^{(k)}=\sum_{s=0}^{h}(-1)^{s}\left(S_{n}(\lambda)^{-1} C_{n}(\rho, \gamma)\right)^{s} S_{n}(\lambda)^{-1} I_{n} \beta_{k}
\end{gathered}
$$

The impact matrices (12) and (13) account for time, spatial and spatio-temporal dynamics in the data to provide the $h$ periods ahead response of $y$ due to a transitory or permanent change in $X_{k}$.

Again, these $n \times n$ impact matrices are full and the analysis in terms of direct, indirect and total effects can also be conducted. Scalar summary measures developed by LeSage \& Pace (2009) can also be used to simplify interpretations.

Expressions (6), (12) and (13) assume that the variation in the $k^{\text {th }}$ determinant is uniform (unit change) across countries. However, in many applications, this homogeneous change assumption may be too strong. For instance, when one faces heterogeneous countries in terms of variation in their economic fundamentals, relaxing this homogeneity variation across countries might be indicated. For instance, if a macroeconomic indicator is more volatile in a first country than in a second, we can expect its changes to be of higher magnitude in the first country compared to the second. We thus propose to generalise expressions (6), (12) and (13) to account for heterogeneous changes in the explanatory variables across countries, which may reflect variations more in line with the real world.

For contemporaneous effects, this generalisation is given in expression (14), where $\Psi_{k}$ is a diagonal matrix with typical diagonal element $\sigma_{k}^{i}$, the historical standard deviation for the $k^{\text {th }}$ determinant for country $i$. In this application, the historical standard deviation is based on quarterly observations from 2008Q1 to 2012Q4 (the estimation period).

\footnotetext{
${ }^{12}$ In this contribution, we use 1999 replications.
} 


$$
\Xi_{t}^{(k)}=S_{n}(\lambda)^{-1} \Psi_{k} \beta_{k}
$$

For diffusion effects based on country-specific transitory changes, expression (12) becomes:

$$
\Xi_{t+h, \text { trans }}^{(k)}=(-1)^{h}\left(S_{n}(\lambda)^{-1} C_{n}(\rho, \gamma)\right)^{h} S_{n}(\lambda)^{-1} \Psi_{k} \beta_{k}
$$

while diffusion effects based on country-specific permanent change, expression (13) becomes:

$$
\Xi_{t+h, p e r m}^{(k)}=\sum_{s=0}^{h}(-1)^{s}\left(S_{n}(\lambda)^{-1} C_{n}(\rho, \gamma)\right)^{s} S_{n}(\lambda)^{-1} \Psi_{k} \beta_{k}
$$

From the interpretative perspective, impacts derived from a homogeneous change in determinants show the effects of accounting for simultaneity in sovereign risk, i.e. modelling interactions between countries' risks. These impacts results in heterogeneous direct effects, but more importantly, this simultaneity implies the presence of indirect effects, which can be quantified. Spatial autoregressive models are, to the best of our knowledge, the only specification which, conditional on the use of an interaction scheme, allows to give a precise quantification of these indirect effects. Under homogeneous changes, partial derivatives indicate the effect interactions have on existence and nature of direct and indirect effects. Considering heterogeneous impacts allows to go one step further and provides more "reality-based" impacts as dynamics in countries' characteristics is accounted for.

It can also be of interest to be able to assess the impacts of an idiosyncratic shock hitting one or several countries simultaneously on the sovereign risk of both the concerned countries and all other countries in the sample. These impacts are also based on the reduced form of the model (equation 5). Let us note $G_{t}$, the diagonal matrix of dimension $n$ collecting idiosyncratic shocks occurring at time $t$ :

$$
G_{t}=\left(\begin{array}{cccc}
g_{1 t} & 0 & \ldots & 0 \\
0 & g_{2 t} & \ldots & 0 \\
\vdots & \vdots & \ddots & \vdots \\
0 & \ldots & \ldots & g_{N t}
\end{array}\right)
$$

If we are only willing to consider a shock in a single country ( $j$ for instance) then we impose all $g_{i t}, i \neq j$ to be 0 . Further, by setting $g_{1 t}=g_{2 t}=\cdots=g_{k t}$, we allow for common shocks affecting simultaneously countries 1 to $k$. The matrix $G_{t}$ is sufficiently general to cover many types of scenario regarding idiosyncratic shocks. 
To assess the impact of idiosyncratic shocks on the sovereign risk, we need to compute the partial derivative of the latter wrt. the former, shown in expression (18).

$$
\frac{\partial y_{t}}{\partial \varepsilon_{t}}=S_{n}(\lambda)^{-1} G_{t} .
$$

Each of its columns contains the effect of an idiosyncratic shock in one country on all the other countries. This is due to the matrix $S_{n}(\lambda)^{-1}$. As such, the direct impact of an idiosyncratic shock in country $i$ on its sovereign risk is calculated as

$$
\frac{\partial y_{i t}}{\partial \varepsilon_{i t}}=\left[S_{n}(\lambda)\right]_{i i} g_{i t}
$$

while the total indirect effect of this shock on all other countries of the sample is obtained from

$$
\sum_{j \neq i}^{n}\left[S_{n}(\lambda)\right]_{j i} g_{i t} .
$$

Alternatively, we can assess the impact on country's $i$ sovereign risk of an idiosyncratic shock hitting other countries of the sample by relying on the following expression:

$$
\sum_{j \neq i}^{n}\left[S_{n}(\lambda)\right]_{i j} g_{j t} .
$$

Those two expressions are the equivalent of (7) and (8) but concern idiosyncratic shocks rather than variations in exogenous determinants.

We can also compute impacts due to a temporary or permanent exogeneous shock using expressions (22) and (23).

$$
\begin{gathered}
{\left[\frac{\partial y_{t+h}}{\partial \varepsilon_{t}}\right]_{\text {trans }}=(-1)^{h}\left(S_{n}(\lambda)^{-1} C_{n}(\rho, \gamma)\right)^{h} S_{n}(\lambda)^{-1} G_{t}} \\
{\left[\frac{\partial y_{t+h}}{\partial \varepsilon_{t}}\right]_{\text {perm }}=\sum_{s=0}^{h}(-1)^{s}\left(S_{n}(\lambda)^{-1} C_{n}(\rho, \gamma)\right)^{s} S_{n}(\lambda)^{-1} G_{t}}
\end{gathered}
$$

To summarize, expressions (18), (22) and (23) indicate how to account for contemporaneous and space-time impacts of idiosyncratic shocks affecting one or several countries simultaneously. 


\section{Results and discussion}

In this section, we present the empirical results of our model. We consider both real linkages and informational transmission channels by using five different interaction matrices. The first interaction matrix is based on bilateral trade flows and models the real linkage transmission channel as done in De Gregorio \& Valdés (2001) and Hernández \& Valdés (2001). The four remaining matrices model informational transmission channels. Similar to Favero (2013), we feature the role of macroeconomic similarities by constructing an interaction matrix from debt-to-GDP similarity and a second one from deficit-to-GDP similarity. Eventually, we go beyond macroeconomic similarity and also consider institutional proximity. Specifically, we construct a third matrix from the government stability index closeness while the last matrix is based on socioeconomic proximity index. ${ }^{13}$ Following the literature, our set of country-specific variables includes standard macroeconomic and financial fundamentals, namely debt-to-GDP ratio, current account balance to GDP ratio, real GDP growth rate, deficit-to-GDP ratio, inflation and the real effective exchange rate, while we consider as global factor the Volatility index (VIX). Table 2 gives further details on the explanatory variables used while Table 3 presents some descriptive statistics.

Proceeding as we do enables us to feature different sources of transmission without having specific prior information on how much each of them can contribute to the transmission mechanism. We then interpret our findings and propose a stress-testing analysis accounting for heterogeneous variations in the determinants across countries. We also group the countries into two categories, advanced and emerging, and perform intra and inter groups stress-testing analysis.

\subsection{Estimation results}

The first five columns of Table 5 summarise the estimation results of model (1) by the quasi-maximum likelihood estimation approach of Yu et al. (2008) for each interaction matrix. ${ }^{14}$

Before analysing the results, we have tested the time-space separability constraint $(\rho=-\lambda \gamma)$. If not rejected, estimation and interpretation of the model are simplified (see Parent \& LeSage 2011, 2012). In our case, this constraint is rejected for all interaction matrices at the $5 \%$ threshold.

One of the key findings of this paper is that all transmission channels considered are

\footnotetext{
${ }^{13}$ The details regarding the empirical construction of interaction matrices are described in Appendix B.

${ }^{14}$ All interaction matrices are row-normalized.
} 
relevant in describing the dynamics of sovereign bond spreads. This interpretation is supported by the fact that both $\lambda$ and $\rho$, which respectively capture contemporaneous and time-lagged interactions between countries are significant. Ignoring interdependences in the analysis of sovereign spreads might thus lead to misspecification issues and therefore erroneous analysis. We also note that the country time-lagged spread is significant $(\gamma \neq 0)$. Further, regardless of the interaction matrix used, the debt-toGDP ratio, inflation and the real effective exchange rate (Reer) are significant with the expected sign. Also the included global risk aversion factor, the $V I X$, is significant. As such, the analysis of parameters' statistical significance indicates that our results are in line with common findings from previous studies on sovereign bond spreads. Such studies, however weakly account for feedback effects from surrounding countries, introducing bias in the estimated impacts of changes in determinants on sovereign risks.

As all transmission channels (modelled by an interaction matrix) are separately relevant, we now want study their individual contribution to the global interaction scheme, namely the one constructed from a convex combination of the interaction matrices. For this, we rely on the methodology described in Section 4.2. In this contribution, two different increments for the values that $\kappa_{i}$ may take are considered: 0.1 and $0.05 .{ }^{15}$ The upper panel of Tables 6 and 7 report the 5 best convex combinations of interaction matrices and the associated log-likelihood value, using an increment of 0.1 and 0.05 respectively. In their lower panel, Tables 6 and 7 report the log-likelihood value when $W^{*}$ is constructed from a single interaction matrix. From these two tables, we observe that increment size does not affect the results. For the two considered values, the optimal combination of interaction matrices allocates a 0.2 weight to the trade channel and a 0.8 weight to socioeconomic proximity. We also observe that transmission channels based on debt-to-GDP ratio, deficit to GDP ratio and government stability do not contribute to the optimal combination. The dominance of socioeconomic similarity that we document over other potential channels such as fiscal similarity as done in Favero (2013) can be explained amid higher stability of socioeconomic conditions (throughout time) and therefore of reliability for investment decisions of market participants. As such, our results complement previous studies documenting the importance of institutional similarity and mitigate the results obtained by Favero (2013) on the role of fiscal fundamental similarity as a channel of transmission. ${ }^{16}$ More generally, this result

\footnotetext{
${ }^{15}$ For an increment of 0.1 for each $\kappa_{i}$, we need to compute the log-likelihood function for 1001 combinations, while for an increment of 0.05 , the log-likelihood value is calculated for 10,626 combinations.

${ }^{16}$ Specifically Dasgupta et al. (2011) have analysed the role of a numerous institutional channels such as similarity in regulatory quality, levels of corruption, business regulation index, government intervention in the banking sector and the Property Rights Index. They find that these institutional channels play a vital role in the spread of all emerging market currency crises.
} 
brings new insight to the literature on the mechanisms contributing to sovereign risk transmission as we are able to compare the relative importance of individual channels with respect to one another.

The last column of Table 5 reports the results using the optimal convex combination of transmission channels, $W^{*}$. The results are quite similar to those based on a single interaction matrix, but as $W^{*}$ combines in the best way the information contained in all channels, economic interpretations of the model will be based on this convex combination.

Before turning to the stress-testing analysis, we would like to summarize the results of our robustness analysis which is fully reported in Appendix C. This complementary set of estimations consists in augmenting our baseline model (Table 5) with variables aimed to feature factors that could simultaneously affect the sovereign risk of specific group of countries. The considered common factor are constructed either from economic variables (MSCI index for group of countries) or from statistical procedures (principal component analysis) with alternative rules for groupings the countries included in our sample. The obtained estimation results confirm our main findings. On the one hand, all parameters capturing the sovereign risk dynamics remain significant. On the other hand, with the exception of the real exchange rate variable in one of the three appended specifications, we find the same significant variables in the the robustness analysis as in our main model.

\section{$5.2 \quad$ Stress-testing analysis}

To keep our analysis simple, we consider only the impact of a change in debt-to-GDP ratio. ${ }^{17}$ Importantly, indirect impacts can be viewed as a measure of international risk spillovers or international exposure. We first study the results for the complete sample (global analysis) and then turn to a group analysis, distinguishing between advanced and emerging countries. We are also able to rank the countries according to their exposure or systemic risk importance. Such a ranking could be used for instance for macroprudential supervision.

\subsubsection{Global analysis}

In this subsection we start by assessing international risk spillovers and exposure considering the complete sample and using the convex combination interaction matrix.

\footnotetext{
${ }^{17}$ All other results are available upon request to the authors.
} 
Table 8 presents, for all significant variables, the scalar summary measures for contemporaneous impacts assuming a uniform variation in the determinants across countries.

We first observe a positive average direct effect for debt-to-GDP ratio, Inflation, VIX and the real exchange rate, implying that on average (across countries), the sovereign risk of a country will increase when one of these variable increases in the concerned country. For instance, if the debt-to-GDP ratio of a country increases by 1 percentage point, its sovereign risk will immediately increase by 2.5 basis points.

Regarding average indirect impacts, no difference is observed if these effects are computed from expression (7) or (8). We thus only report one value for the average indirect effects.

However, by contrast to direct effects, the real exchange rate variable does not have significant indirect effects. Only debt-to GDP ratio, inflation and VIX will have positive and significant indirect effects. For instance, if the debt-to-GDP increases by 1 percentage point in a given country, on average, we observe a cumulative increase of 5 basis points in the sovereign spreads of all the other countries. Turning to the alternative explanation (i.e. international exposure), if the debt-to-GDP ratio increases by 1 percentage point in all countries but one, the sovereign risk of that country will increase by 5 basis points (while its debt-to-GDP ratio does not change). The measure of these indirect effects constitutes an important contribution of spatial autoregressive models as global effects of local changes are accounted for explicitly.

Finally, average total effects for debt-to-GDP ratio, inflation, VIX and real exchange rate are significant and positive, with a much higher level than direct effects. This implies that if the debt-to-GDP ratio increases in all countries by 1 percentage point, the sovereign spread of a given country will on average increase by 7.5 basis points, a value three times superior to the direct effect ( 2.5 basis points). This first analysis shows the importance of measuring the global effect (including direct and indirect) of a change in a determinant and not only the local (direct) effect.

Figure 2 compares contemporaneous impacts when partial derivatives wrt. debt-toGDP ratios are evaluated using uniform variation (left panels) and a vector of countryspecific standard deviations (right panels). We report the direct, and indirect effects for each country. ${ }^{18}$ Indirect effects are computed using expression (8), assessing the international exposure of each country.

As noted in Section 4.3, direct effects are heterogeneous by nature but in our application, when partial derivative wrt. the debt-to-GDP ratio is evaluated using a uniform variation, this heterogeneity is quite moderate. The highest direct effect is for Belgium (0.0252) while the weakest is for Indonesia, Tunisia and South Africa (0.0245). Turning

\footnotetext{
${ }^{18}$ As our interaction matrix is row-normalized, total effects are constant when partial derivatives are evaluated using an uniform change in a determinant (see LeSage \& Pace 2009, p.40).
} 
to country-specific debt-to-GDP changes, we observe a much higher magnitude and heterogeneity among direct effects. As such, Ireland (0.7276), followed by Greece (0.4803) and Portugal (0.4588) are the countries where the sovereign spread is the most reactive to a change in their own debt-to-GDP ratio. This can be explained by the historical higher volatility of their debt-to-GDP ratio. But we also note that Belgium is one of the most reactive countries. The country with the least reactive sovereign spread to a change in its debt-to-GDP ratio is Bulgaria. Accounting for country-specific historical variation in debt-to-GDP produces different conclusions regarding the most and least vulnerable sovereign spreads to change in own-countries debt-to-GDP ratio (direct effects).

The bottom panels of Figure 2 depict international exposure of each country. The magnitude and volatility of the indirect effects are much higher when partial derivarives are evaluated using a vector of country-specific historical standard deviations changes. The right panel shows that Switzerland, and Sweden to a lesser extent, are the most fragile countries when the debt-to-GDP ratio increases in all other countries. Indeed, the Swiss sovereign spread will increase by 35.23 basis points when the debt-to-GDP ratio of each country increases by one country's historical standard deviation. However, Venezuelan sovereign spread is the least sensitive to a change in all other countries as it only increases by 28.23 basis points. By comparison, when the partial derivatives are evaluated using a uniform variation (left panel), the most fragile countries are Indonesia, Pakistan, Tunisia and South Africa (increase of the sovereign spread of 5.14 basis points), while the least fragile are Belgium and Germany (increase by 5.08 basis points). We also note that indirect effects are higher for advanced countries (blue stars) than for emerging countries (red stars).

In addition to fitting more closely to realistic variation, the country-specific change analysis highlights what we call the bad neighbours effect. Indeed, a strong interaction with highly volatile debt-to-GDP ratio countries implies a stronger reaction of the sovereign spread when the debt-to-GDP of these countries change, while if a country is only affected by stable countries (in terms of the volatility of their economic fundamentals) its sovereign spread will show a more moderate reaction. Let us note that this bad neighbours effects cannt be identified when partial derivatives are evaluated using a uniform change as the determinant change is the same for all countries. In this application, we see that Switzerland, and Mexico to a lesser extent, are affected by the bad neighbours effect as they are relatively more affected than the other countries when we account for country-specific changes in the debt-to-GDP ratio than when uniform variations.

Along with the analysis of contemporaneous impacts of a change in some determinants, our econometric specification allows us to study diffusion (spatio-temporal) 
impacts. However, due to the heterogeneity between groups of countries (advanced versus emerging) we postpone the study and interpretation of these effects to the next section.

\subsubsection{Group of countries analysis}

This section focuses on the risk transmission across advanced and emerging countries. More precisely, we investigate the extent to which a change in the macroeconomic conditions in all advanced countries affects the sovereign risk in each emerging (and vice-versa). Within each group, we also identify the most fragile countries. Finally, we compare the impacts obtained using the bilateral trade similarity, the socioeconomic closeness and the optimal convex combination.

Figure 3 depicts contemporaneous impacts based on country-specific variations of the debt-to-GDP ratio for interaction matrices based on bilateral trade, socioeconomic proximity and the optimal convex combination. Black bars measure direct effects while indirect effects (measuring international exposure) are represented by the white bars. Panel A represents impacts due to a change in all advanced countries only, while Panel B displays impacts due to a change in all emerging countries. We first interpret the results based on the best interaction matrix, $W^{*}$, displayed in the first column of Figure 3 and then compare with those obtained for the two other interaction matrices.

Several points are worth highlighting. Direct effects for advanced countries are on average higher than those for emerging countries (0.228 vs 0.079). On average, sovereign spreads in advanced countries are thus more reactive to change in their debtto-GDP ratio than sovereign spreads of emerging countries regarding their own debtto-GDP ratio. Also, when a group of countries (advanced or emerging) is hit by a macroeconomic distress, impacts are not confined to the countries of the affected group, but spread to all other countries. For instance, when the debt-to-GDP ratio increases in all advanced countries (Panel A Figure 3), the sovereign spread of all emerging countries is affected, and particularly Latin American countries (Mexico and Chile), Asian (Malaysia and China) and to a lesser extent Hungary. However, a change in debt-to-GDP ratio from emerging countries (Panel B Figure 3) has a less pronounced impact on advanced countries. Also, the average indirect effect on emerging countries equals 0.195 when the debt-to-GDP ratio in all advanced countries is hit while this value for advanced countries when the debt-to-GDP ratio in all emerging countries varies is 0.067 . Figure 3 well illustrates the asymmetry with respect to international risk exposure between groups.

When macroeconomic distress hits all advanced countries, we note that Ireland, followed by Greece and Portugal are the most fragile advanced countries. Venezuela 
and Ukraine constitute the most fragile emerging countries due to a shock in all of these countries. However, the sovereign spread response is much higher for the three first aforementioned countries than for the last two.

We also compare the impacts based on $W^{*}$ with those using the bilateral trade or socio-economic proximity by looking at second and third column of Figure 3. As expected, impacts computed using $W^{*}$ are quite close to those based on the informational transmission channel since $W^{*}$ is a convex combination giving $80 \%$ weight to socio-economic proximity. However, they are not completely equal due to the $20 \%$ contribution of bilateral trade.

Finally, we analyse diffusion impacts of the debt-to-GDP ratio, namely the future response of sovereign spreads due to either a transitory or permanent variation of the debt-to-GDP ratio in the current period. Figure 4 displays the diffusion impacts of country-specific variations on the debt-to-GDP ratio, its left panel showing the effects of a transitory variation while the right panel focuses on the impacts resulting from a permanent change. In each of the six sub-figures, we report the value of one scalar summary measure (ADE, AIE, ATE) for the whole sample (in green), for advanced (in blue) and emerging countries (in red). Regarding transitory changes, the average direct effect is significant up to 17 periods after the variation. However, the average indirect effect loses its significance after the initial period and the average total effect remains significant one period after the variation. We observe that the ADE for advanced countries is the highest, compared to the global analysis and emerging countries. This implies that the future responses of sovereign spread of advanced countries will be larger than those of emerging countries. As the model is stationary, we also note that significant impacts are monotonically decreasing over time. The right panel of Figure 4 displays impacts due to a permanent change in debt-to-GDP ratio, computed as the sum of transitory changes. For permanent changes, we only report the value of the impact, not considering its significance. We note that the average total effect associated with a permanent change flattens much faster than for average direct effects.

\section{Conclusions}

The unfolding financial crisis in 2008 followed by the sovereign crisis in the Eurozone have revamped the interest in the international transmission of risk and stressed the importance of continuing research despite the large amount of academic contributions on contagion or financial spillovers. In this paper we analyse the role of real linkages and informational channels in the transmission of sovereign risk across countries. For this, we estimate a spatial dynamic panel data model that explicitly accounts for time, spatial and spatio-temporal dependence in sovereign risks. This specification allows us to 
quantify indirect effects, which, in our paper, can either assess the fragility of sovereign spread of a country to a change in determinants in other countries or assess its risk spillovers. We also propose to compute impacts based on country-specific fundamentals changes, which reflect more reality-based changes in determinants than standard impact analysis which assume homogeneous variation across countries. Further, we also implement the Hazir et al. (2016) methodology to find the convex combination of transmission channels which model interactions in the best way. We are thus able to identify countries whose environments are most at risk and those which are the most exposed to international risk.

Our analysis, based on a large sample of both advanced and emerging countries, reveals that real linkages and informational channels are all separately relevant to explain risk transmission. However, when combined, it turns out that the global interaction scheme is made of socioeconomic proximity $(80 \%)$ and of bilateral trade flows (20\%). This indicates that investors seem to particularly account for informational channel characterised by the similarity in terms of socioeconomic conditions. Additionally, our stress testing procedure reveals that a change in the macroeconomic conditions of emerging countries has less impact on the sovereign risk of the advanced countries. On the other hand, deterioration of the macroeconomic environment in advanced countries will have a more pronounced impact on emerging economies. Finally, we find that the effect of a change in the macroeconomic conditions of a country tends to be higher within the block of countries it belongs to.

Our analysis emphasizes several interesting features of international economic spillovers and raises questions that open new avenues for research, some of them being presented below. First, by empirically documenting the role of cross-country spillovers effects over a large set of both advanced and emerging economies, our study supports the ongoing efforts done in the literature to include interactions among world-economies in the structure of theoretical models. More specifically, our findings tend to stress two important features for future developments of macroeconomic models such as multicountry DSGE: (i) the co-existence of multiple transmission channels and (ii) among operating channels the critical role of informational channel. By testing and quantifying the effect of alternative transmission channels, our spatial econometrics approach may also be extremely useful in the parametrization of theoretical models. Second, our analysis also sheds light on a set of promising extensions of the econometric estimation approach used to quantify and explore spillovers' effects. Hence, the spatial dynamic panel data specification with individual fixed effects used to model sovereign risk is based on homogeneous coefficients across countries (excepted for the intercept). However, accounting for cross-sectional dependence implies heterogeneous impacts. In 
static panel data frameworks, several papers have derived heterogeneous coefficients versions of the traditional homogeneous SAR specification. (see, for further details Aquaro et al. 2015, Blasques et al. 2016, LeSage \& Chih 2017). The GVAR also allows for heterogeneous coefficients between countries. Nevertheless, in this modelling approach, accounting for contemporaneous interactions between countries requires strong assumptions on the construction of foreign variables (see Pesaran et al. 2004, section 7). Deriving the heterogeneous coefficients version of the specification we consider could constitute an interesting research path and would further exacerbate the heterogeneity of impacts found here. Finally, in this paper, we assess how a change in some exogenous determinant will affect sovereign risk, both in the considered country and in all others countries of the sample. This reasoning is performed conditional on the interaction scheme. Instead of studying the impact of determinants on sovereign risk, an alternative approach consists in assessing the role of the interaction scheme on countries' risk. Changes in countries' risk exposure (or transmission) would rely on variations in the nature of interactions between countries. In such a framework, we could evaluate the counterfactual effect of a change in the interaction scheme on the sovereign risk. We however leave this interesting and promising approach for further research.

\section{Acknowledgments}

Nicolas Debarsy and Cem Ertur acknowledge financial support of the Region Centre Val de Loire (APR-IA 2014 00094514). Jean-Yves Gnabo acknowledges financial support of the ARC grant (Projet d'Actions de Recherche Concertées) \#13/17-055 granted by the Académie universitaire Louvain. Cyrille Dossougoin acknowledges the financial support of the FRS - FNRS. We would also like to thank the editor and two anonymous referees, Sophie Béreau, Christian Brownlees, Etienne Farvaque, Sofia Franco, Zhengyuan Gao, Eric Kolaczyk, James LeSage, Jérémy Leymarie, Gori Maia, Jihai Yu and participants at the $26^{\text {th }}(\mathrm{EC})^{2}$ conference, $15^{\text {th }}$ International Workshop in Spatial Econometrics and Statistics, $11^{\text {th }}$ Spatial Econometrics Association meeting, $15^{\text {th }}$ workshop in Econometrics (Paris Ouest-Nanterre la Défense), Doctoral workshop of University of Namur and University of Orléans and the Lille Research Workshop on Statistics and Econometrics. All remaining errors are ours.

\section{References}

Acemoglu, D., Carvalho, V. M., Ozdaglar, A. \& Tahbar-Salehi, A. (2012), 'The network origins of aggregate fluctuations', Econometrica 80, 1977-2016. 
Acemoglu, D., Ozdaglar, A. \& Tahbaz-Salehi, A. (2015), 'Systemic risk and stability in financial networks', American Economic Review 105(2), 564-608.

Acharya, V. V., Heje Pederson, L., Philippon, T. \& Richardson, M. (2017), 'Measuring systemic risk', Review of Financial Studies 30(1), 2-47.

Adrian, T. \& Brunnermeier, M. K. (2016), 'Covar', American Economic Review 106(7), 1705-41.

Aizenman, J., Jinjarak, Y. \& Park, D. (2013a), 'Capital flows and economic growth in the era of financial integration and crisis, 1990-2010', Open Economies Review 24(3), 371-396.

Aizenman, J., Jinjarak, Y. \& Park, D. (2013b), Fundamentals and sovereign risk of emerging markets, Working Paper 18963, National Bureau of Economic Research.

Alessandrini, P., Fratianni, M., Hughes Hallett, A. \& Presbitero, A. F. (2014), 'External imbalances and fiscal fragility in the euro area', Open Economies Review 25(1), 3-34.

Allen, F. \& Babus, A. (2009), Networks in finance, in 'The Network Challenge: Strategy, Profit, and Risk in an Interlinked', Wharton School Publishing, Philadelphia, PA, USA, pp. 367-382.

Allen, F. \& Gale, D. (2000), 'Financial contagion', The Journal of Polical Economic 108(1), 1-33.

Alpanda, S. \& Aysun, U. (2014), 'International transmission of financial shocks in an estimated DSGE model', Journal of International Money and Finance 47(C), 21-55.

Anselin, L. (1988), Spatial Econometrics: Methods and Models, Vol. 4, Springer Netherlands.

Anselin, L. \& Bera, A. (1998), Spatial dependence in linear regression models with an application to spatial econometrics, in A. Ullah \& D. Giles, eds, 'Handbook of Applied Economics Statistics', Marcel Dekker, New York, pp. 237-289.

Anselin, L., Le Gallo, J. \& Jayet, H. (2008), Spatial panel econometrics, in L. Matyas \& P. Sevestre, eds, 'The Econometrics of Panel Data', Kluwer Academic Publishers, Dordrecht.

Antonakakis, N. \& Vergos, K. (2013), 'Sovereign bond yield spillovers in the Euro zone during the financial and debt crisis', Journal of International Financial Markets, Institutions and Money 26, 258-272. 
Aquaro, M., Bailey, N. \& Pesaran, H. M. (2015), Quasi maximum likelihood estimation of spatial models with heterogeneous coefficients, CESIFO Working Paper 5428.

Arghyrou, M. G. \& Kontonikas, A. (2012), 'The EMU sovereign-debt crisis: Fundamentals, expectations and contagion', Journal of International Financial Markets, Institutions and Money 22(4), 658-677.

Attinasi, M.-G., Checherita-Westphal, C. \& Nickel, C. (2009), What explains the surge in euro area sovereign spreads during the financial crisis of 2007-09?, Working Paper Series 1131, European Central Bank.

Bae, K., Karolyi, A. \& Stulz, R. (2003), 'A new approach to measuring financial contagion', Review of Financial Studies 16, 717-763.

Battiston, S., Caldarelli, G., D'Errico, M. \& Gurciullo, S. (2017), 'Leveraging the network: A stress-test framework based on DebtRank', Statistics \& Risk Modeling 33(34), 117-138.

Battiston, S., Delli Gatti, D., Gallegati, M., Greenwald, B. \& Stiglitz, J. (2012), 'Liaisons dangereuses: Increasing connectivity, risk sharing, and systemic risk', Journal of Economic Dynamics and Control 36, 1121-1141.

Beine, M., Cosma, A. \& Vermeulen, R. (2010), 'The dark side of global integration: Increasing tail dependence', Journal of Banking \& Finance 34(1), 184-192.

Beirne, J. \& Fratzscher, M. (2013), 'The pricing of sovereign risk and contagion during the european sovereign debt crisis', Journal of International Money and Finance 34, 60-82.

Bekaert, G., Harvey, C. R. \& Ng, A. (2005), 'Market integration and contagion', The Journal of Business 78(1), 39-70.

Bernoth, K. \& Erdogan, B. (2012), 'Sovereign bond yield spreads: A time-varying coefficient approach', Journal of International Money and Finance 31, 639-656.

Bisias, D., Flood, M., Lo, A. W. \& Valavanis, S. (2012), 'A survey of systemic risk analytics', Annual Review of Financial Economics 4, 255-296.

Blasques, F., Koopman, S. J., Lucas, A. \& Schaumburg, J. (2016), 'Spillover dynamics for systemic risk measurement using spatial financial time series models', Journal of Econometrics 195(2), 211-223. 
Blau, P. M. (1974), 'Presidential address: Parameters of social structure', American Sociological Review 39(5), 615-635.

Bordo, M. D., M., T. A. \& Williamson, J. G., eds (1999), Globalization in Historical Perspective, Chicago: University of Chicago Press.

Bostanci, G. \& Yilmaz, K. (2015), How connected is the global sovereign credit risk network?, Working Paper 1515, Koç University-TUSIAD Economic Research Forum.

Bramoullé, Y., Djebbari, H. \& Fortin, B. (2009), 'Identification of peer effects through social networks', Journal of Econometrics 150(1), 41-55.

Broto, C. \& Pérez-Quiros, G. (2015), 'Disentangling contagion among sovereign CDS spreads during the European debt crisis', Journal of Empirical Finance 32, 165-179.

Brownlees, C. T. \& Engle, R. F. (2017), 'SRISK: A conditional capital shortfall measure of systemic risk', The Review of Financial Studies 30, 48-79.

Burt, R. S. (1981), 'Studying status/role-sets as ersatz network positions in mass surveys', Sociological Methods \& Research 9(3), 313-337.

Calvò-Armengol, A., Patacchini, E. \& Zenou, Y. (2009), 'Peer effects and social networks in education', Review of Economic Studies 76, 1239-1267.

Candelon, B., Carare, A. \& Miao, K. (2016), 'Revisiting the new normal hypothesis', Journal of International Money and Finance 66(Supplement C), 5-31.

Centola, D. (2011), 'An experimental study of homophily in the adoption of health behavior', Science 334(6060), 1269-1272.

Christiano, L. J., Eichenbaum, M. \& Evans, C. L. (2005), 'Nominal rigidities and the dynamic effects of a shock to monetary policy', Journal of Political Economy $113(1), 1-45$.

Christiano, L. J., Motto, R. \& Rostagno, M. (2014), 'Risk shocks', American Economic Review 104(1), 27-65.

Cipriani, M., Guarino, A., Guazzarotti, G., Tagliati, F. \& Fischer, S. (2015), Informational contagion in the laboratory, Staff reports, Federal Reserve Bank of New York.

Codogno, L., Favero, C. \& Missale, A. (2003), 'Yield spreads on EMU government bonds', Economic Policy 18(37), 503-532. 
Coudert, V. \& Gex, M. (2010), 'Credit default swap and bond markets: which leads the other?', Financial Stability Review 14, 161-167.

Csonto, B. \& Ivaschenko, I. V. (2013), Determinants of Sovereign Bond Spreads in Emerging Markets : Local Fundamentals and Global Factors vs. Ever-Changing Misalignments, Technical report, International Monetary Fund.

Dagum, E. B. \& Cholette, P. A. (2006), Benchmarking, Temporal Distribution, and Reconciliation Methods for Time Series, Springer.

Dasgupta, A., Leon-Gonzalez, R. \& Shortland, A. (2011), 'Regionality revisited: An examination of the direction of spread of currency crises', Journal of International Money and Finance 30(5), $831-848$.

Davis, S. \& Presno, I. (2014), Capital Controls as an Instrument of Monetary Policy, Working Paper 171, Federal Reserve Bank of Dallas.

De Grauwe, P. \& Ji, Y. (2013), 'Self-fulfilling crises in the Eurozone: An empirical test', Journal of International Money and Finance 34, 15-36.

De Gregorio, J. \& Valdés, R. O. (2001), 'Crisis transmission: Evidence from the debt, tequila, and asian flu crises', The World Bank Economic Review 15(2), 289-314.

De Santis, R. A. (2012), The Euro area sovereign debt crisis: safe haven, credit rating agencies and the spread of the fever from Greece, Ireland and Portugal, Working Paper Series, European Central Bank.

De Walque, G., Lejeune, T., Rychalovska, Y. \& Wouters, R. (2017), An estimated two-country EA-US model with limited exchange rate pass-through, Working Paper Research 317, National Bank of Belgium.

Debarsy, N. \& Ertur, C. (2010), 'Testing for spatial autocorrelation in a fixed effects panel data model', Regional Science and Urban Economics 40, 453-470.

Debarsy, N., Ertur, C. \& LeSage, J. P. (2012), 'Interpreting dynamic space-time panel data models', Statistical Methodology 9, 158-171.

Dedola, L., Karadi, P. \& Lombardo, G. (2013), 'Global implications of national unconventional policies', Journal of Monetary Economics 60(1), 66-85.

Di Cesare, A., Grande, G., Manna, M. \& Taboga, M. (2012), Recent estimates of sovereign risk premia for euro-area countries, Occasional Paper 128, Bank of Italy. 
Diebold, F. X. \& Yilmaz, K. (2014), 'On the network topology of variance decompositions: Measuring the connectedness of financial firms', Journal of Econometrics 182(1), 119-134.

Diebold, F. X. \& Yilmaz, K. (2015), Financial and Macroeconomic Connectedness: A Network Approach to Measurement and Monitoring, Oxford University Press.

Dungey, M., Fry, R., Gonzalez-Hermosillo, B. \& Martin, V. (2005), 'Contagion: Understanding how it spreads', Quantitative Finance 1(5), 9--24.

Eichengreen, B., Rose, A. K. \& Wyplosz, C. (1996), Contagious Currency Crises, Working Paper 5681, National Bureau of Economic Research.

Elliott, M., Golub, B. \& Jackson, M. O. (2014), 'Financial networks and contagion', American Economic Review 104(10), 3115-3153.

Faia, E. (2007), 'Finance and international business cycles', Journal of Monetary Economics 54(4), 1018-1034.

Faini, R. (2006), 'Fiscal policy and interest rates in Europe', Economic Policy $\mathbf{2 1}(47), 443-489$.

Favero, C. A. (2013), 'Modelling and forecasting government bond spreads in the euro area: A GVAR model', Journal of Econometrics 177, 343-356.

Favero, C. \& Missale, A. (2012), 'Sovereign spreads in the eurozone: which prospects for a eurobond?', Economic Policy 27(70), 231-273.

Favero, C., Pagano, M. \& von Thadden, E.-L. (2010), 'How does liquidity affect government bond yields?', The Journal of Financial and Quantitative Analysis 45(1), 107134.

Forbes, K. J. \& Rigobon, R. (2002), 'No contagion, only interdependence: Measuring stock market comovements', The Journal of Finance 57(5), 2223-2261.

Forbes, K. J. \& Warnock, F. E. (2012), 'Capital flow waves: Surges, stops, flight, and retrenchment', Journal of International Economics 88(2), 235-251.

Forbes, K. \& Rigobon, R. (2001), Measuring contagion: Conceptual and empirical issues, in 'International Financial Contagion', Springer, pp. 43-66.

Frankel, J. A. \& Rose, A. K. (1996), The Endogeneity of the Optimum Currency Area Criteria, Working Paper 5700, National Bureau of Economic Research. 
Fratzscher, M. (2012), 'Capital flows, push versus pull factors and the global financial crisis', Journal of International Economics 88(2), 341-356.

Gai, P. \& Kapadia, S. (2010), 'Contagion in financial networks', Proceedings of the Royal Society of London A: Mathematical, Physical and Engineering Sciences 466(2120), 2401-2423.

Galí, J. \& Monacelli, T. (2005), 'Monetary Policy and Exchange Rate Volatility in a Small Open Economy', Review of Economic Studies 72(3), 707-734.

Georgiadis, G. \& Jančokovà, M. (2017), Financial globalisation, monetary policy spillovers and macro-modelling: Tales from 1001 shocks, Working Paper 314, Federal Reserve Bank of Dallas.

Gerlach, S., Schulz, A. \& Wolff, G. B. (2010), Banking and sovereign risk in the euro area, Discussion Paper Series 1: Economic Studies 09, Deutsche Bundesbank, Research Centre.

Gertler, M. \& Karadi, P. (2011), 'A model of unconventional monetary policy', Journal of Monetary Economics 58(1), 17-34.

Ghironi, F. (2000), Towards new open economy macroeconometrics, Staff Reports 100, Federal Reserve Bank of New York.

Giordano, R., Pericoli, M. \& Tommasino, P. (2013), 'Pure or Wake-up-Call Contagion? Another Look at the EMU Sovereign Debt Crisis', International Finance 16(2), 131160 .

Giorgino, T. (2009), 'Computing and visualizing dynamic time warping alignments in r: The dtw package', Journal of Statistical Software, Articles 31(7), 1-24.

Gnabo, J.-Y. \& Scholtes, N. (2016), Assessing the role of interbank network structure in business and financial cycle analysis, Working Paper Research 307, National Bank of Belgium.

Goldstein, M. \& Woglom, G. (1991), Market-Based Fiscal Discipline in Monetary Unions; Evidence From the U.S. Municipal Bond Market, Working Papers 91/89, International Monetary Fund.

Grossman, G. M. \& Helpman, E. (2014), Growth, trade, and inequality, Working Paper 20502, National Bureau of Economic Research. 
Hazir, C. S., LeSage, J. \& Autant-Bernard, C. (2016), 'The role of R\&D collaboration networks on regional innovation performance', Papers in Regional Science, Forthcoming .

Hernández, L. F. \& Valdés, R. O. (2001), 'What drives contagion: trade, neighborhood of financial links?', International Review of Financial Analysis 10(3), 203-218.

Hondroyiannis, G., Kelejian, H. H. \& Tavlas, G. S. (2010), Government bond spread contagion among the European countries, Technical Report 6, Bank of Greece.

Hüser, A.-C. (2015), Too interconnected to fail: A survey of the interbank networks literature, Working Paper 91, Research Center SAFE, Goethe University Frankfurt.

Jackson, M. O. (2010), Social and Economic Network, Princeton University Press, Princeton.

Justiniano, A. \& Preston, B. (2010), 'Can structural small open-economy models account for the influence of foreign disturbances?', Journal of International Economics 81(1), 61-74.

Kaminsky, G. L. \& Reinhart, C. M. (2000), 'On crises, contagion, and confusion', Journal of International Economics 51(1), 145-168.

Karolyi, G. A. (2003), 'Does international financial contagion really exist?', International Finance 6(2), 179-199.

Kelejian, H. H. \& Prucha, I. R. (1998), 'A generalized spatial two stage least squares procedure for estimating a spatial autoregressive model with autoregressive disturbances', Journal of Real Estate Finance and Economics 17, 99-121.

Kilponen, J., Laakkonen, H. \& Vilmunen, J. (2015), 'Sovereign risk, European crisisresolution policies, and bond spreads', International Journal of Central Banking 11(2), 285-323.

King, M. A. \& Wadhwani, S. (1990), 'Transmission of volatility between stock markets', Review of Financial Studies 3(1), 5-33.

Kireyev, A. \& Leonidov, A. (2015), Network effects of international shocks and spillovers, Working Paper 15/149, International Monetary Fund.

Kodres, L. E., Hartelius, K. \& Kashiwase, K. (2008), Emerging Market Spread Compression; Is it Real or is it Liquidity?, Working Papers 08/10, International Monetary Fund. 
Kodres, L. E. \& Pritsker, M. (2002), 'A rational expectations model of financial contagion', Journal of Finance 57, 768-799.

Kohonen, A. (2014), 'Transmission of government default risk in the eurozone', Journal of International Money and Finance 47, 71-85.

König, M., Robner, D., Thoenig, M. \& Zilibotti, F. (2017), 'Networks in conflict: Theory and evidence from the great war of africa', Econometrica 85(4), 1093-1132.

Kumar, M. S., Jonás̃, J. \& Hauner, D. (2007), Policy Credibility and Sovereign Credit; The Case of New EU Member States, Working Papers 07/1, International Monetary Fund.

Laubach, T. (2009), 'New evidence on the interest rate effects of budget deficits and debt', Journal of the European Economic Association 7(4), 858-885.

Lee, L.-F. (2004), 'Asymptotic distributions of quasi-maximum likelihood estimators for spatial autoregressive models', Econometrica 72, 1899-1925.

Lee, L.-F. \& Yu, J. (2014), 'Efficient GMM estimation of spatial dynamic panel data models with fixed effects', Journal of Econometrics 180, 174-197.

LeSage, J. \& Chih, Y.-Y. (2017), 'A bayesian spatial panel model with heterogeneous coefficients', Regional Science and Urban Economics, Forthcoming .

LeSage, J. \& Pace, R. K. (2009), Introduction to Spatial Econometrics, CRC Press.

Lubik, T. \& Schorfheide, F. (2006), A bayesian look at the new open economy macroeconomics, in 'NBER Macroeconomics Annual 2005', Vol. 20, National Bureau of Economic Research, Inc, pp. 313-382.

Maltritz, D. (2012), 'Determinants of sovereign yield spreads in the Eurozone: A Bayesian approach', Journal of International Money and Finance 31(3), 657-672.

Masson, P. R. (1998), Contagion: Monsoonal effects, spillovers, and jumps between multiple equilibria, Working Paper 98/142, International Monetary Fund.

Monfort, A. \& Renne, J.-P. (2011), Credit and liquidity risks in euro area sovereign yield curves, Working papers 352, Banque de France.

Newman, M. (2010), Networks: an introduction, Oxford University Press, New-York. 
Obstfeld, M. \& Rogoff, K. (1995), The mirage of fixed exchange rates, Working Paper 5191, National Bureau of Economic Research.

Ord, K. (1975), 'Estimation methods for models of spatial interaction', Journal of the American Statistical Association 70, 120-126.

Parent, O. \& LeSage, J. P. (2011), 'A space-time filter for panel data models containing random effects', Computational Statistics and Data Analysis 55, 475-490.

Parent, O. \& LeSage, J. P. (2012), 'Spatial dynamic panel data models with random effects', Regional Science and Urban Economics 42, 727-738.

Pesaran, H. M., Schuermann, T. \& Weiner, S. M. (2004), 'Modeling regional interdependencies using a global error-correcting macroeconometric model', Journal of Business and Economic Statistics 22, 129-162.

Poterba, J. \& Rueben, K. (1999), State fiscal institutions and the u.s. municipal bond market, in 'Fiscal Institutions and Fiscal Performance', National Bureau of Economic Research, pp. 181-208.

Pritsker, M. (2001), The Channels for financial contagion, in S. Claessens \& K. J. Forbes, eds, 'International Financial Contagion', Springer, pp. 67-95.

Rabanal, P. \& Tuesta, V. (2010), 'Euro-dollar real exchange rate dynamics in an estimated two-country model: An assessment', Journal of Economic Dynamics and Control 34(4), 780-797.

Rajan, R. G. (2005), Has financial development made the world riskier?, Working Paper 11728, National Bureau of Economic Research.

Schwarz, K. (2017), Mind the Gap: Disentangling Credit and Liquidity in Risk Spreads, Working papers, University of Pennsylvania, Wharton School, Philadelphia, PA.

Sims, C. A. (1980), 'Macroeconomics and Reality', Econometrica 48(1), 1-48.

Singh, J. (2005), 'Collaborative Networks as Determinants of Knowledge Diffusion Patterns', Management Science 51(5), 756-770.

Smets, F. \& Wouters, R. (2007), 'Shocks and frictions in us business cycles: A bayesian dsge approach', American Economic Review 97(3), 586-606. 
Strahilov, K. (2006), The determinants of country risk in eastern european countries. evidence from sovereign bond spreads, Policy Paper 8, Bruges European Economic Research.

Stulz, R. M. (2007), 'The limits of financial globalization', Journal of Applied Corporate Finance 19(1), 8-15.

von Hagen, J., Schuknecht, L. \& Wolswijk, G. (2011), 'Government bond risk premiums in the EU revisited: The impact of the financial crisis', European Journal of Political Economy 27(1), 36-43.

Yao, W. (2012), International Business Cycles and Financial Frictions, Staff Working Papers 12-19, Bank of Canada.

Yu, J., de Jong, R. \& Lee, L.-F. (2008), 'Quasi-maximum likelihood estimators for spatial dynamic panel data with fixed effects when both $\mathrm{n}$ and $\mathrm{T}$ are large', Journal of Econometrics 146(1), 118-134. 
Table 1: List of countries

\begin{tabular}{|c|c|c|c|}
\hline \multicolumn{2}{|c|}{ ADVANCED } & \multicolumn{2}{|c|}{ EMERGING } \\
\hline Country & ISO code & Country & ISO code \\
\hline \multicolumn{2}{|c|}{ Europe } & \multicolumn{2}{|c|}{ Europe } \\
\hline Austria & AUT & Bulgaria & BGR \\
\hline Belgium & BEL & Hungary & HUN \\
\hline Finland & FIN & Poland & POL \\
\hline France & FRA & Turkey & TUR \\
\hline Germany & $\mathrm{DEU}$ & Ukraine & UKR \\
\hline Greece & GRC & Russia & RUS \\
\hline Ireland & IRL & \multicolumn{2}{|c|}{ Asia } \\
\hline Italy & ITA & China & $\mathrm{CHN}$ \\
\hline Netherlands & NLD & Indonesia & IDN \\
\hline Portugal & PRT & Malaysia & MYS \\
\hline Spain & ESP & Philippines & PHL \\
\hline Denmark & DNK & \multicolumn{2}{|c|}{ Latin America } \\
\hline Norway & NOR & Argentina & ARG \\
\hline Sweden & SWE & Brazil & BRA \\
\hline Switzerland & $\mathrm{CHE}$ & Chile & CHL \\
\hline United Kingdom & GBR & Colombia & $\mathrm{COL}$ \\
\hline \multicolumn{2}{|c|}{ America } & Mexico & MEX \\
\hline \multirow[t]{2}{*}{ Canada } & \multirow[t]{2}{*}{$\mathrm{CAN}$} & Peru & PER \\
\hline & & Uruguay & URY \\
\hline \multicolumn{2}{|c|}{ Australia and Asia } & Venezuela & VEN \\
\hline Australia & AUS & \multicolumn{2}{|c|}{ Middle east and Africa } \\
\hline Japan & JPN & Pakistan & PAK \\
\hline \multirow[t]{2}{*}{ Korea } & KOR & Tunisia & TUN \\
\hline & & South Africa & $\mathrm{ZAF}$ \\
\hline
\end{tabular}

Note: Countries are assigned to groups according to the IMF classification of countries as defined in the World Economic Outlook report (April 2012). 
Table 2: Description of variables used in the regression

\begin{tabular}{|c|c|c|c|c|c|}
\hline Variable & Definition & $\begin{array}{l}\text { Original } \\
\text { frequency }\end{array}$ & $\begin{array}{l}\text { Frequency conver- } \\
\text { sion method }\end{array}$ & Source & $\begin{array}{l}\text { Expected } \\
\text { sign }\end{array}$ \\
\hline \multicolumn{6}{|c|}{ Dependent variable } \\
\hline \multirow[t]{2}{*}{ BYS } & $\begin{array}{l}\text { Advanced countries: } 10 \text {-year government bond yield mi- } \\
\text { nus US treasury bond yield of the same maturity }\end{array}$ & Daily & Average & Datastream & \\
\hline & $\begin{array}{l}\text { Emerging countries: 10-year Emerging Market Bond In- } \\
\text { dex Global (EMBIG) }\end{array}$ & Daily & Average & GEM-WB & \\
\hline \multicolumn{6}{|c|}{ Country-specific explanatory variables } \\
\hline \multirow{2}{*}{ debt/GDP } & General Government gross debt over GDP & Quarterly $^{a}$ & - & $\mathrm{OECD}^{a}$ & + \\
\hline & & Annual $^{e}$ & $\begin{array}{l}\text { Denton-Cholette } \\
\text { method }\end{array}$ & $\mathrm{WEO}^{e}$ & \\
\hline \multirow[t]{2}{*}{ def/GDP } & General government net lending/borrowing over GDP & Quarterly $^{a}$ & - & $\mathrm{OECD}^{a}$ & + \\
\hline & & Annual $^{e}$ & $\begin{array}{l}\text { Denton-Cholette } \\
\text { method }\end{array}$ & $\mathrm{WEO}^{e}$ & \\
\hline \multirow[t]{2}{*}{ current/GDP } & Current account balance over GDP & Quarterly $^{a}$ & - & $\mathrm{OECD}^{a}$ & - \\
\hline & & Annual $^{e}$ & $\begin{array}{l}\text { Denton-Cholette } \\
\text { method }\end{array}$ & $\mathrm{WEO}^{e}$ & \\
\hline \multirow[t]{2}{*}{ inflation } & Consumer price indices & Monthly & Average & $\mathrm{OECD}^{a}$ & + \\
\hline & & & & Macrobond $^{e}$ & \\
\hline \multirow[t]{2}{*}{ GDP growth } & Real GDP growth rate & Quarterly $^{a}$ & - & $\mathrm{OECD}^{a}$ & - \\
\hline & & Annual $^{e}$ & $\begin{array}{l}\text { Denton-Cholette } \\
\text { method }\end{array}$ & $\mathrm{WEO}^{e}$ & \\
\hline \multicolumn{6}{|c|}{ Global explanatory variables } \\
\hline VIX & Implied volatility of S\&P 500 index options & Daily & Average & Datastream & + \\
\hline Reer & Real effective exchange rate & Monthly & Average & Bruegel & $+/-$ \\
\hline
\end{tabular}

Notes: The superscripts "a" and "e" refer respectively to advanced and emerging countries. For advanced countries the macroeconomic variables are available at the quarterly frequency, while for emerging we only have annual observations. We then have recourse to the Denton-Cholette method to retrieve quarterly data (see Dagum \& Cholette 2006, p.80, 82). GEM-WB: Global Economic Monitor of the World Bank database; WEO: IMF World Economic Outlook.

Table 3: Descriptive statistics of the variables

\begin{tabular}{lccccc}
\hline & Mean & St. Dev. & Median & Min & Max \\
\hline Sovereign bond yield spread (\%) & 2.536 & 3.713 & 1.694 & -2.378 & 31.923 \\
Debt/GDP *100 & 55.790 & 37.058 & 45.045 & 4.147 & 234.995 \\
Deficit/GDP *100 & -3.115 & 5.443 & -2.769 & -40.240 & 21.640 \\
Current account/GDP *100 & -0.006 & 5.796 & -0.778 & -25.488 & 18.100 \\
Inflation rate (\%) & 1.029 & 1.371 & 0.779 & -3.050 & 9.984 \\
GDP growth (\%) & 0.374 & 1.362 & 0.500 & -6.900 & 4.800 \\
Risk aversion (VIX) & 25.750 & 10.082 & 23.677 & 16.193 & 58.596 \\
Real effective exchange rate (wrt USD) & 100.901 & 10.841 & 99.530 & 69.010 & 155.180 \\
\hline
\end{tabular}


Table 4: Correlation between variables

\begin{tabular}{lrrrrrrr}
\hline & debt/GDP & def/GDP & current/GDP & inflation & GDP_Growth & VIX & reer \\
\hline debt/GDP & 1 & & & & & & \\
def/GDP & $\mathbf{- 0 . 3 5 5}$ & 1 & & & & & \\
current/GDP & $\mathbf{- 0 . 0 8 1}$ & $\mathbf{0 . 2 9 7}$ & 1 & & & & \\
inflation & $\mathbf{- 0 . 2 1 0}$ & $\mathbf{- 0 . 0 6 7}$ & -0.061 & 1 & & \\
GDP Growth & $\mathbf{- 0 . 2 0 6}$ & $\mathbf{0 . 1 1 3}$ & $\mathbf{0 . 0 7 3}$ & $\mathbf{0 . 1 2 5}$ & & \\
VIX & -0.064 & 0.022 & -0.041 & $\mathbf{- 0 . 1 2 4}$ & $\mathbf{- 0 . 3 8 9}$ & 1 & \\
Reer & $\mathbf{0 . 0 8 4}$ & 0.039 & 0.057 & $\mathbf{0 . 1 1 3}$ & $\mathbf{0 . 1 9 0}$ & $\mathbf{- 0 . 1 1 8}$ & 1 \\
\hline
\end{tabular}

Note: This table reports Pearson's correlation between control variables. Figures in bold indicate that the correlation is significant at $5 \%$ confidence level.

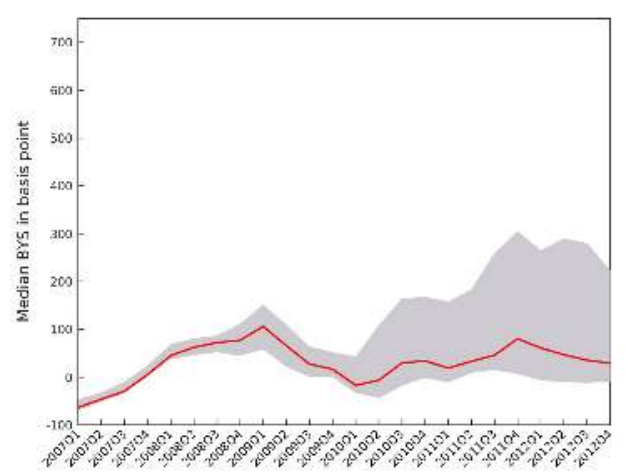

(a) Advanced countries

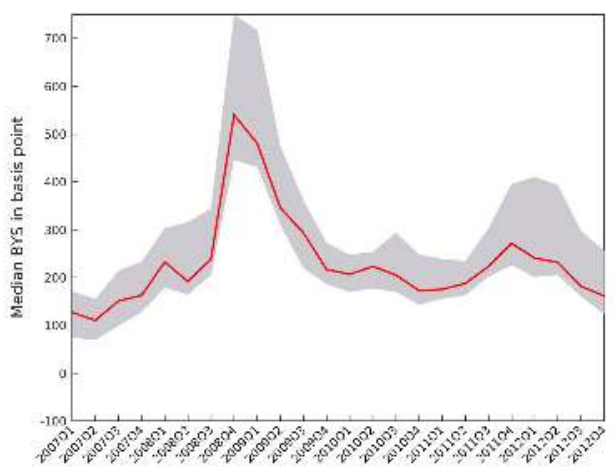

(b) Emerging countries

Figure 1: Median of government bond yield spreads over time. The shaded areas represent the interquartile range. 
Table 5: Estimation results with alternative trade-based interaction matrices

\begin{tabular}{|c|c|c|c|c|c|c|}
\hline Variables & Trade & Debt & Deficit & Gvt stability & Socio_eco & $W^{*}$ \\
\hline$Y_{t-1}$ & $\begin{array}{c}0.844^{* * *} \\
(0.022)\end{array}$ & $\begin{array}{c}0.832^{* * *} \\
(0.023)\end{array}$ & $\begin{array}{c}0.845^{* * *} \\
(0.023)\end{array}$ & $\begin{array}{c}0.841^{* * *} \\
(0.023)\end{array}$ & $\begin{array}{c}0.860^{* * *} \\
(0.022)\end{array}$ & $\begin{array}{c}0.859^{* * *} \\
(0.022)\end{array}$ \\
\hline$W Y_{t-1}$ & $\begin{array}{c}-0.619^{* * *} \\
(0.066)\end{array}$ & $\begin{array}{c}-0.460^{* * *} \\
(0.076)\end{array}$ & $\begin{array}{c}-0.534^{* * *} \\
(0.072)\end{array}$ & $\begin{array}{c}-0.539^{* * *} \\
(0.073)\end{array}$ & $\begin{array}{c}-0.690^{* * *} \\
(0.059)\end{array}$ & $\begin{array}{c}-0.705^{* * *} \\
(0.059)\end{array}$ \\
\hline$W Y_{t}$ & $\begin{array}{c}0.568^{* * *} \\
(0.054)\end{array}$ & $\begin{array}{c}0.403^{* * *} \\
(0.079)\end{array}$ & $\begin{array}{c}0.469^{* * *} \\
(0.080)\end{array}$ & $\begin{array}{c}0.477^{* * *} \\
(0.080)\end{array}$ & $\begin{array}{c}0.674^{* * *} \\
(0.051)\end{array}$ & $\begin{array}{c}0.686^{* * *} \\
(0.048)\end{array}$ \\
\hline debt/GDP & $\begin{array}{c}0.027^{* * *} \\
(0.006)\end{array}$ & $\begin{array}{c}0.031^{* * *} \\
(0.006)\end{array}$ & $\begin{array}{c}0.029^{* * *} \\
(0.006)\end{array}$ & $\begin{array}{c}0.030^{* * *} \\
(0.006)\end{array}$ & $\begin{array}{c}0.024^{* * *} \\
(0.006)\end{array}$ & $\begin{array}{c}0.024^{* * *} \\
(0.006)\end{array}$ \\
\hline def/GDP & $\begin{array}{c}0.012 \\
(0.014)\end{array}$ & $\begin{array}{c}0.011 \\
(0.014)\end{array}$ & $\begin{array}{c}0.006 \\
(0.014)\end{array}$ & $\begin{array}{c}0.008 \\
(0.014)\end{array}$ & $\begin{array}{c}0.002 \\
(0.014)\end{array}$ & $\begin{array}{c}0.003 \\
(0.014)\end{array}$ \\
\hline current/GDP & $\begin{array}{l}-0.012 \\
(0.018)\end{array}$ & $\begin{array}{l}-0.022 \\
(0.019)\end{array}$ & $\begin{array}{l}-0.022 \\
(0.019)\end{array}$ & $\begin{array}{l}-0.024 \\
(0.019)\end{array}$ & $\begin{array}{c}-0.02 \\
(0.018)\end{array}$ & $\begin{array}{l}-0.018 \\
(0.018)\end{array}$ \\
\hline inflation & $\begin{array}{c}0.172^{* * *} \\
(0.052)\end{array}$ & $\begin{array}{c}0.195^{* * *} \\
(0.054)\end{array}$ & $\begin{array}{c}0.188^{* * *} \\
(0.054)\end{array}$ & $\begin{array}{c}0.187^{* * *} \\
(0.054)\end{array}$ & $\begin{array}{c}0.169^{* * *} \\
(0.052)\end{array}$ & $\begin{array}{c}0.167^{* * *} \\
(0.051)\end{array}$ \\
\hline GDP growth & $\begin{array}{l}-0.004 \\
(0.043)\end{array}$ & $\begin{array}{l}-0.001 \\
(0.045)\end{array}$ & $\begin{array}{l}-0.002 \\
(0.044)\end{array}$ & $\begin{array}{l}-0.007 \\
(0.045)\end{array}$ & $\begin{array}{l}-0.004 \\
(0.042)\end{array}$ & $\begin{array}{l}-0.004 \\
(0.042)\end{array}$ \\
\hline VIX & $\begin{array}{c}0.037^{* * *} \\
(0.006)\end{array}$ & $\begin{array}{c}0.042^{* * *} \\
(0.007)\end{array}$ & $\begin{array}{c}0.037^{* * *} \\
(0.007)\end{array}$ & $\begin{array}{c}0.037^{* * *} \\
(0.007)\end{array}$ & $\begin{array}{c}0.027^{* * *} \\
(0.006)\end{array}$ & $\begin{array}{c}0.027^{* * *} \\
(0.006)\end{array}$ \\
\hline Reer & $\begin{array}{l}0.016^{* *} \\
(0.007)\end{array}$ & $\begin{array}{l}0.017^{* *} \\
(0.007)\end{array}$ & $\begin{array}{l}0.017^{* *} \\
(0.007)\end{array}$ & $\begin{array}{l}0.017^{* *} \\
(0.007)\end{array}$ & $\begin{array}{l}0.015^{* *} \\
(0.007)\end{array}$ & $\begin{array}{l}0.015^{* *} \\
(0.007)\end{array}$ \\
\hline Country FE & Yes & Yes & Yes & Yes & Yes & Yes \\
\hline $\operatorname{LogL}$ & -1251.882 & -1274.894 & -1268.957 & $\begin{array}{l}-1270.198 \\
\end{array}$ & $\begin{array}{l}-1242.036 \\
\end{array}$ & -1241.162 \\
\hline NT: & 779 & 779 & 779 & 779 & 779 & 779 \\
\hline $\mathrm{N}:$ & 41 & 41 & 41 & 41 & 41 & 41 \\
\hline $\begin{array}{l}H_{0}: \rho=-\lambda \gamma \\
\text { Stat: } \\
\text { p-value: }\end{array}$ & $\begin{array}{l}6.638 \\
0.010\end{array}$ & $\begin{array}{l}4.885 \\
0.027\end{array}$ & $\begin{array}{l}6.032 \\
0.014\end{array}$ & $\begin{array}{l}6.001 \\
0.014\end{array}$ & $\begin{array}{l}4.937 \\
0.026\end{array}$ & $\begin{array}{l}5.027 \\
0.025\end{array}$ \\
\hline
\end{tabular}

Notes: $* *$ and $* * *$ denote significance at the , $5 \%$ and $1 \%$ respectively. Standard deviations are between brackets. $W^{*}$ is the optimal convex combination of all the channels: $W^{*}=0.2 *$ Trade $+0.8 *$ Socio_eco. 
Table 6: Models ranking with convex combinations of interaction matrices, increment of 0.1

\begin{tabular}{ccccccc}
\hline Rank & $\kappa_{1}$ & $\kappa_{2}$ & $\kappa_{3}$ & $\kappa_{4}$ & $\kappa_{5}$ & $\log L$ \\
\hline \multicolumn{1}{c}{ Top five combinations } \\
\hline 1 & 0.2 & 0 & 0 & 0 & 0.8 & -1241.162 \\
2 & 0.3 & 0 & 0 & 0 & 0.7 & -1241.292 \\
3 & 0.1 & 0 & 0 & 0 & 0.9 & -1241.417 \\
4 & 0.4 & 0 & 0 & 0 & 0.6 & -1241.811 \\
5 & 0 & 0 & 0 & 0 & 1 & -1242.036 \\
\hline \multicolumn{1}{c}{ Single interaction matrix } \\
\hline 5 & 0 & 0 & 0 & 0 & 1 & -1242.036 \\
149 & 1 & 0 & 0 & 0 & 0 & -1251.882 \\
911 & 0 & 0 & 1 & 0 & 0 & -1268.957 \\
949 & 0 & 0 & 0 & 1 & 0 & -1270.198 \\
1001 & 0 & 1 & 0 & 0 & 0 & -1274.894 \\
\hline
\end{tabular}

Table 7: Models ranking with convex combinations of interaction matrices, increment of 0.05

\begin{tabular}{ccccccc}
\hline Rank & $\kappa_{1}$ & $\kappa_{2}$ & $\kappa_{3}$ & $\kappa_{4}$ & $\kappa_{5}$ & $\log L$ \\
\hline \multicolumn{7}{c}{ Top five combinations } \\
\hline 1 & 0.2 & 0 & 0 & 0 & 0.8 & -1241.162 \\
2 & 0.25 & 0 & 0 & 0 & 0.75 & -1241.184 \\
3 & 0.15 & 0 & 0 & 0 & 0.85 & -1241.235 \\
4 & 0.3 & 0 & 0 & 0 & 0.7 & -1241.292 \\
5 & 0.1 & 0 & 0 & 0 & 0.9 & -1241.417 \\
\hline \multicolumn{7}{c}{ Single interaction matrix } \\
\hline 9 & 0 & 0 & 0 & 0 & 1 & -1242.036 \\
1511 & 1 & 0 & 0 & 0 & 0 & -1251.882 \\
10001 & 0 & 0 & 1 & 0 & 0 & -1268.957 \\
10329 & 0 & 0 & 0 & 1 & 0 & -1270.198 \\
10626 & 0 & 1 & 0 & 0 & 0 & -1274.894 \\
\hline
\end{tabular}


Table 8: Scalar summary measures of contemporaneous impacts for significant variables

\begin{tabular}{|c|c|c|c|}
\hline & Lower $2.5 \%$ & Mean & Upper $97.5 \%$ \\
\hline & \multicolumn{3}{|c|}{ Average Direct Effect } \\
\hline debt/GDP & 0.013 & 0.025 & 0.037 \\
\hline inflation & 0.071 & 0.174 & 0.277 \\
\hline VIX & 0.017 & 0.029 & 0.040 \\
\hline \multirow[t]{2}{*}{ Reer } & 0.002 & 0.016 & 0.030 \\
\hline & \multicolumn{3}{|c|}{ Average Indirect Effects } \\
\hline debt/GDP & 0.016 & 0.051 & 0.085 \\
\hline inflation & 0.082 & 0.355 & 0.623 \\
\hline VIX & 0.033 & 0.058 & 0.083 \\
\hline \multirow[t]{2}{*}{ Reer } & -0.0001 & 0.032 & 0.064 \\
\hline & \multicolumn{3}{|c|}{ Average Total Effects } \\
\hline debt/GDP & 0.032 & 0.075 & 0.119 \\
\hline inflation & 0.169 & 0.529 & 0.889 \\
\hline VIX & 0.053 & 0.087 & 0.119 \\
\hline Reer & 0.003 & 0.048 & 0.093 \\
\hline
\end{tabular}


Contemporaneous impacts, $\Delta x_{i}=1 \quad$ Contemporaneous impacts, $\Delta x_{i}=\sigma^{i}$
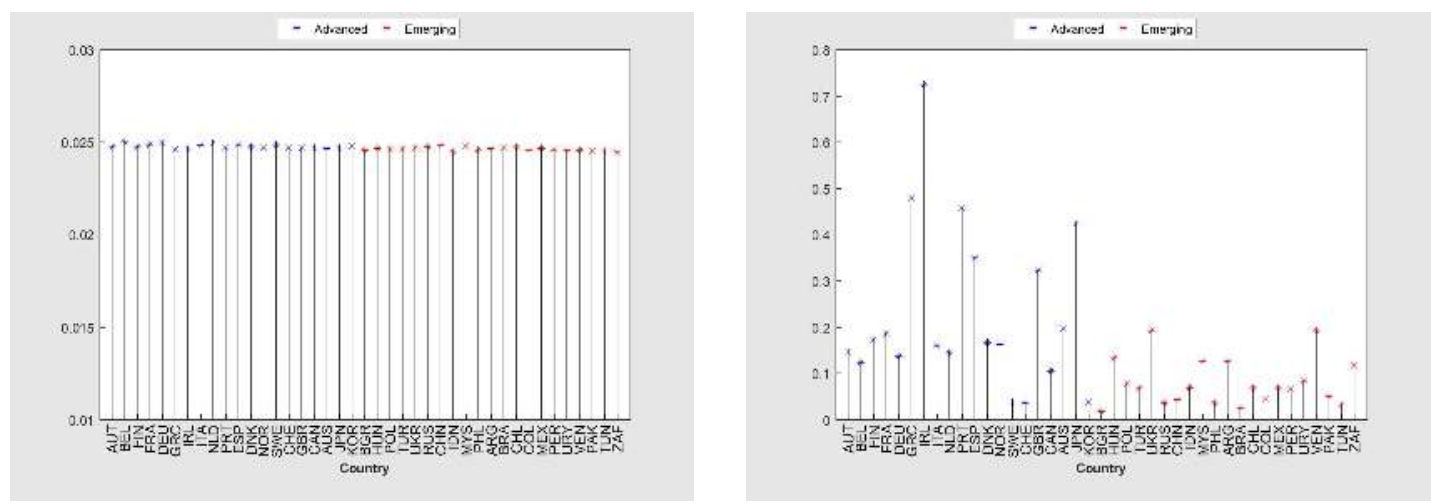

Panel A: Direct effects
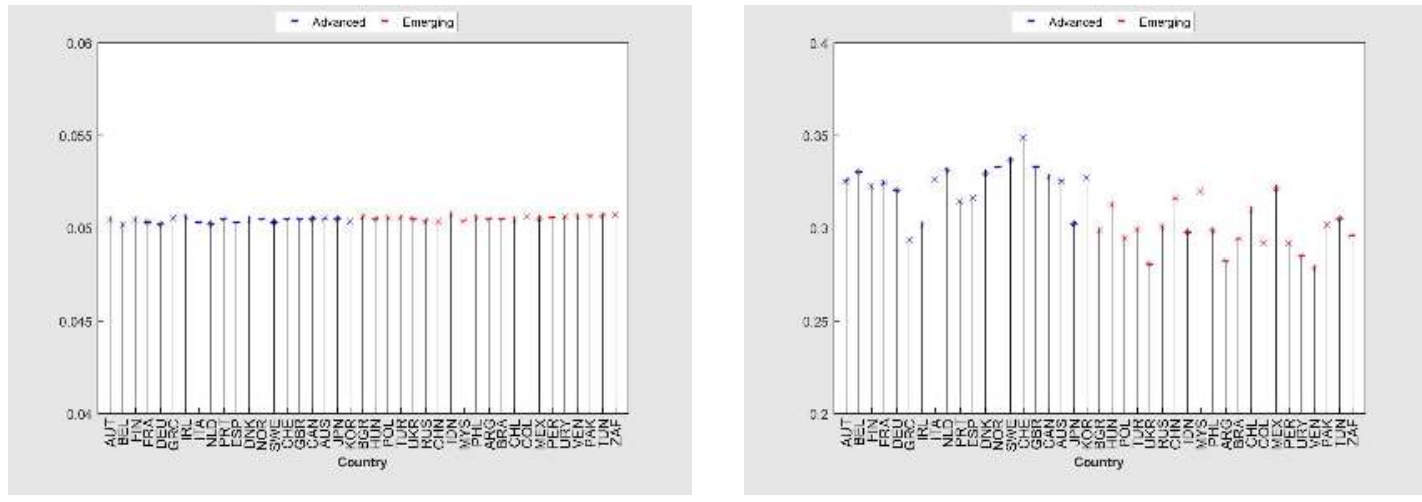

\section{Panel B: Indirect effects}

Figure 2: Contemporaneous impact of a change in debt-to-GDP ratio using $W^{*}=$ $0.2 *$ Trade $+0.8 *$ Socio_eco

Note: $\Delta x_{i}=1$ corresponds to homogeneous variation in the debt-to-GDP ratio across countries. However, $\Delta x_{i}=\sigma^{i}$ refers to country specific variation of the debt-to-GDP ratio, where $\sigma^{i}$ is the historical standard deviation based on quarterly data over 2008Q1-2012Q4. 

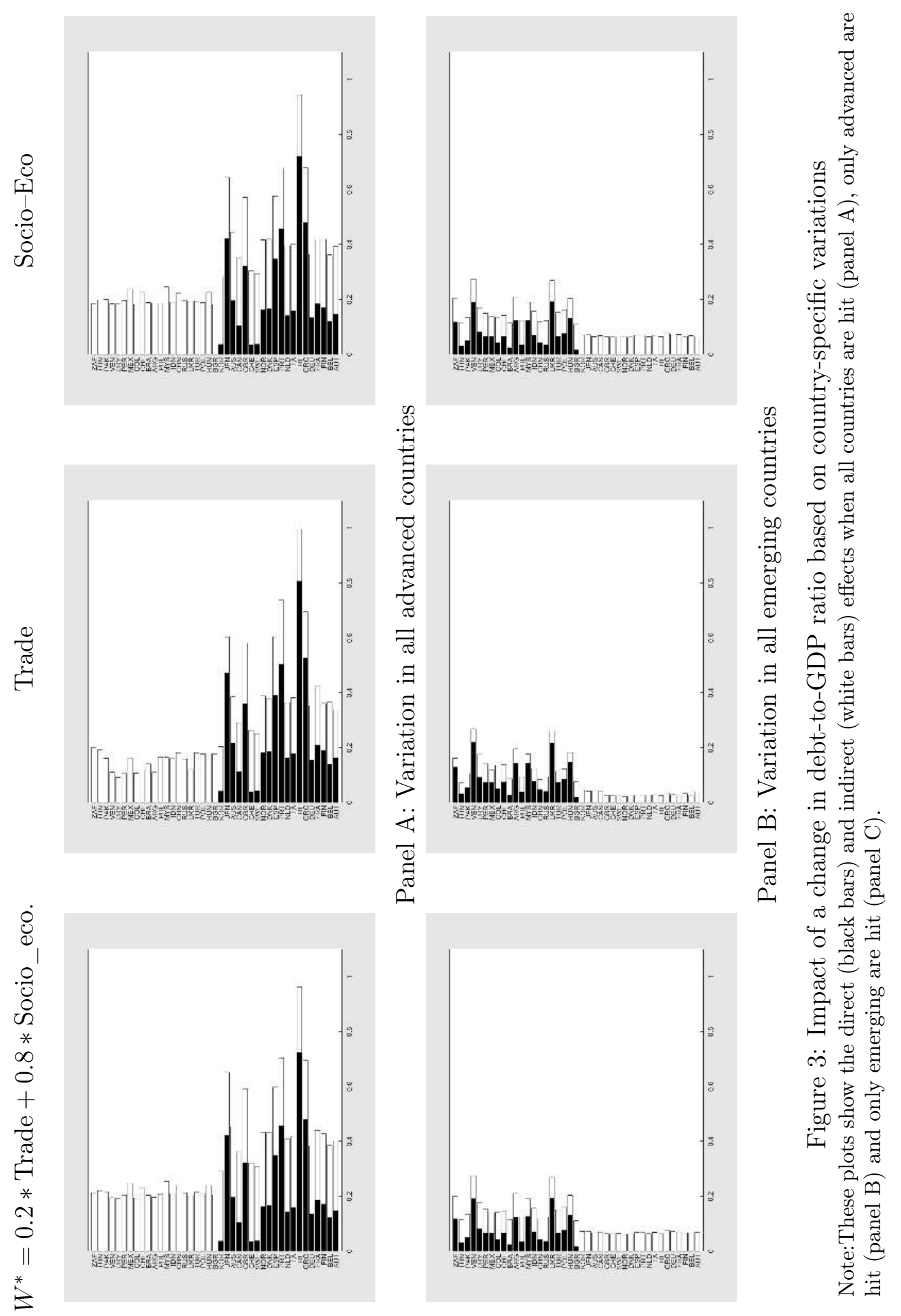


\section{A Determinants of sovereign risk}

In what follows, we review in detail the main body of the literature on sovereign bond spreads' baseline determinants.

The whole set of determinants is generally broken down into three main categories: credit risk, liquidity risk factors and global risk components.

Credit risk factors aim to depict a country's ability to meet its financial obligations vis-a-vis its creditors. They mainly involve fiscal as well as macroeconomic fundamentals. Variables such as public debt and deficit reflect the credibility of the government to repay its creditors and impact the perceived quality of sovereign credit (Kumar et al. 2007). Fiscal variables have been found to significantly influence bond spreads. For instance, Goldstein \& Woglom (1991) and Poterba \& Rueben (1999) among others, found a positive impact of US states' public debt on their bond yield. Laubach (2009) finds a positive relationship between fiscal deficit and spreads. Similar effects have been established for European countries by Faini (2006) although differences across countries (Codogno et al. 2003) and periods (von Hagen et al. 2011, Favero \& Missale 2012, Aizenman et al. 2013a, Bernoth \& Erdogan 2012) regularly appear. Specifically, von Hagen et al. (2011) show that the contribution of fiscal imbalances to sovereign spreads drastically rose during the financial crisis. Likewise, Alessandrini et al. (2014) find that heavily indebted countries were more penalised after 2010.

Besides fiscal fundamentals, other macroeconomic factors also influence credit default risk. The business cycle, captured by real GDP growth or the output gap, is often incorporated as a control variable (Gerlach et al. 2010). In theory, the current account also has an important role as a signal of a country's net lending or borrowing position on international markets (Strahilov 2006). Accordingly, countries with a negative balance are expected to face higher debt repayment as external debt increases. In keeping with this argument, De Grauwe \& Ji (2013) find that a worsening of the current account is indeed penalised by the market, which requires higher spreads. Maltritz (2012) provides a more contrasted view on this mechanism, arguing that a positive current account may also signal the inability of a country to borrow from abroad or signals capital flight, and therefore be associated with widening of spreads. It is therefore not clear from the literature which effects dominate.

Liquidity risk factors embed the size and depth of the bond market. Unlike credit risk variables, liquidity risk variables are often not directly observable. As a result, the literature on industrialised countries has used different proxies for country-specific liquidity factors, while contributions including emerging economies have generally not 

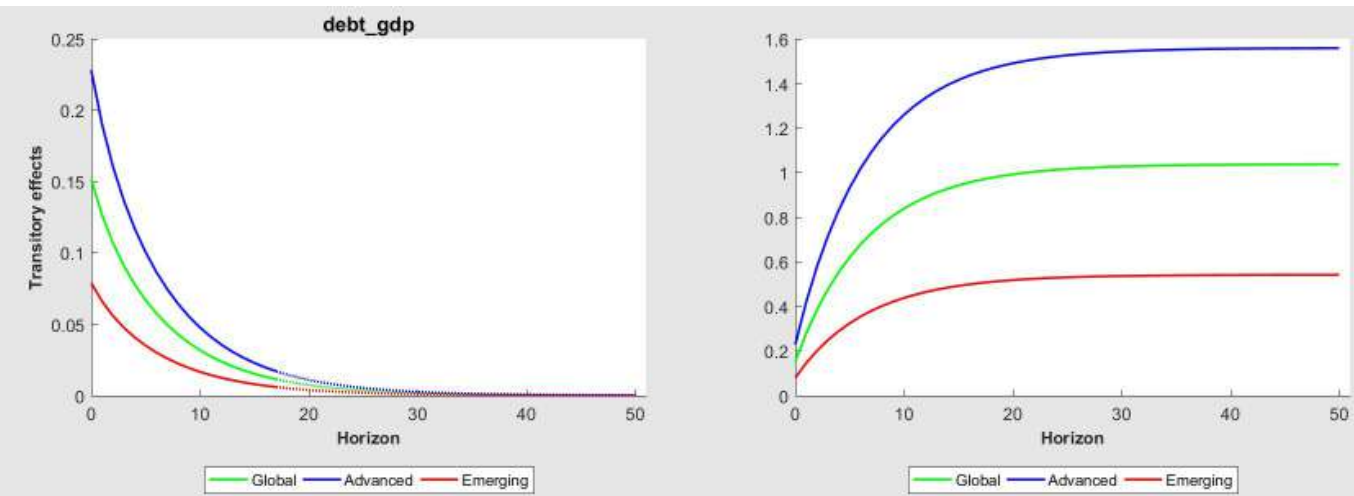

Panel A: Direct effects
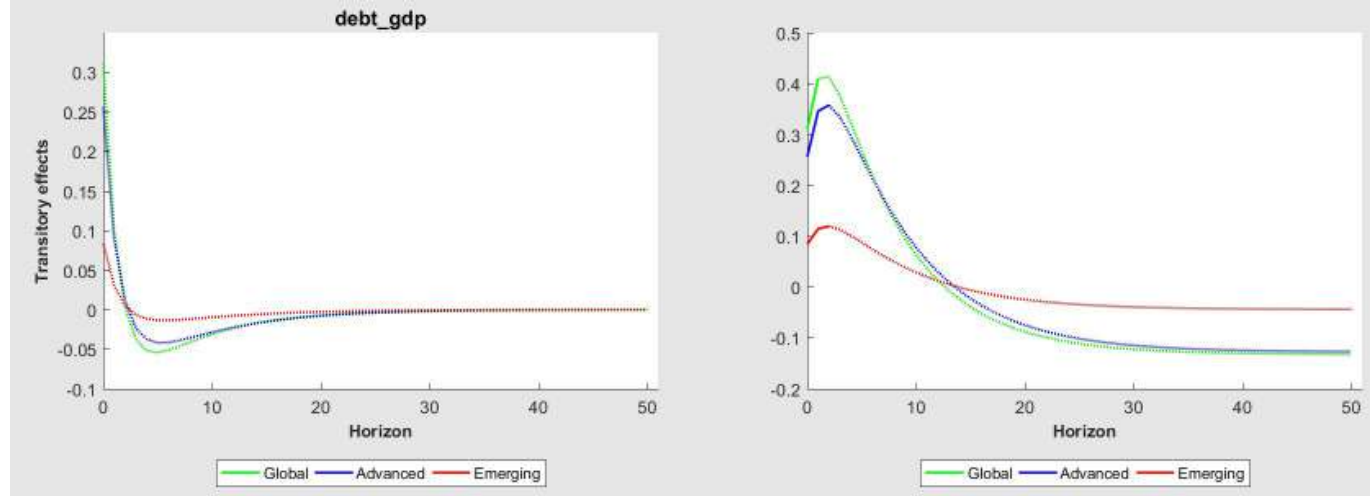

Panel B: Indirect effects
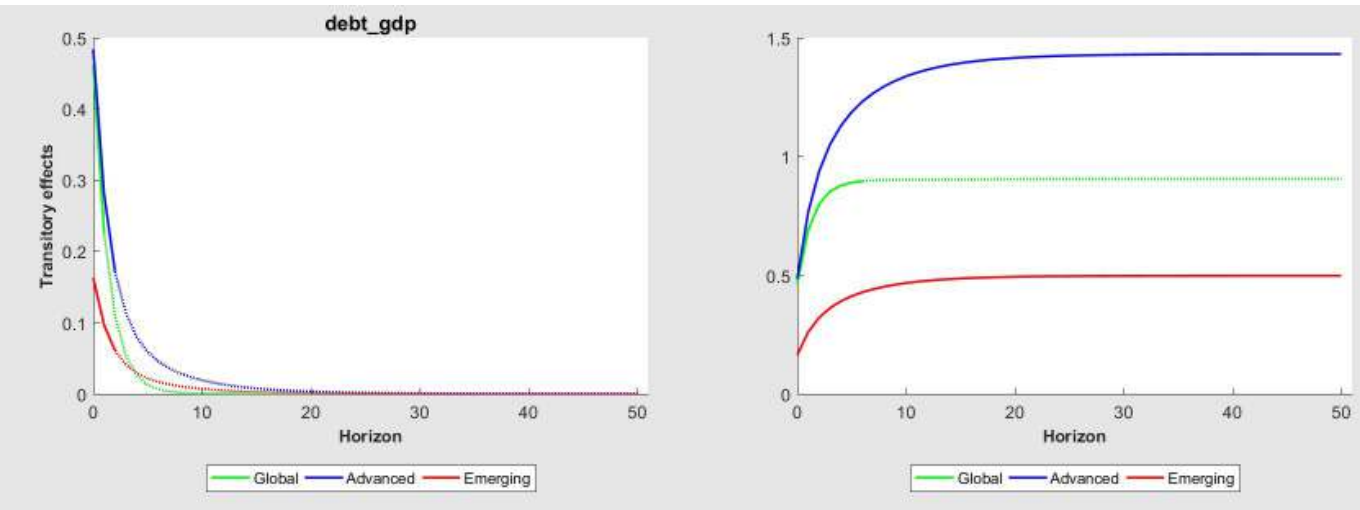

\section{Panel C: Total effects}

Figure 4: Diffusion impacts of a change in debt-to-GDP ratio using $W^{*}=0.2 *$ Trade+ $0.8 *$ Socio_eco

Note: $\Delta x_{i}=\bar{\sigma}^{i}$ refers to country specific variation $50 \mathrm{f}$ the debt-to-GDP ratio, where $\sigma^{i}$ is the historical standard deviation based on quarterly data over 2008Q1-2012Q4. For transitory changes, a dashed line indicates non-significant impacts (at $5 \%$ threshold) while a solid line indicates significant impacts. For permanent changes, we only report the value of the impact, regardless of its significance. 
explicitly included them in the model (Aizenman et al. 2013b, Beirne \& Fratzscher 2013). Among the proxies considered in the literature, several contributions use the bidask spread (Gerlach et al. 2010, Bernoth \& Erdogan 2012, De Santis 2012, Favero 2013, Kilponen et al. 2015). Alternatively, others rely on the yield spreads between bonds of national agencies and government bonds (see Monfort \& Renne 2011, De Santis 2012, Kilponen et al. 2015, Schwarz 2017). In general, liquidity risk is found to be significant in explaining the government bond yield spreads (Attinasi et al. 2009, Gerlach et al. 2010, Arghyrou \& Kontonikas 2012, Favero \& Missale 2012, Giordano et al. 2013) with nevertheless some exceptions (see for instance Bernoth \& Erdogan 2012).

Recent research has also emphasised the critical role of global risk components which capture general market conditions. Among others, Gerlach et al. (2010), von Hagen et al. (2011), Arghyrou \& Kontonikas (2012), Bernoth \& Erdogan (2012), Favero \& Missale (2012). Favero et al. (2010) and Di Cesare et al. (2012) emphasise the critical role of a general risk aversion factor in the sharp increase of the spreads during the recent European debt crisis. More specifically, the authors point out market participants' concerns regarding a possible breakdown of the Eurozone. Regarding emerging market countries, Csonto \& Ivaschenko (2013) and Kodres et al. (2008) also found that a global risk factor plays an important role in explaining the yield spreads in the 90's. A last strand of the literature has apprehended the impact of international environment through the occurrence of "domino effects" in the vein of the seminal works of Pritsker (2001) and Forbes \& Rigobon (2001). Among recent contributions we can quote Arghyrou \& Kontonikas (2012), Antonakakis \& Vergos (2013) or Kilponen et al. (2015).

\section{B Construction of interaction matrices}

One key element in our empirical work is the characterisation of the transmission channels identified in the theoretical literature (real links and informational channels). To this end we use real data and measures of similarity/intensity. We collected statistical data on commercial transactions as well as macroeconomic and socioeconomic indicators over the period 2000 to 2007 to construct our interaction matrices. We did not use data after 2007 to avoid endogeneity problems. Additionally, we used low frequency data to obtain a more robust measure of interaction and avoid statistical artifacts. The rest of this appendix describes the construction of our interaction matrices. 


\section{Interaction matrix based on real economic links transmission channels}

This type of channel encompasses all commercial and financial transactions that create links favourable to a transmission of risk across countries. For the purpose of our analysis, we collect annual data on bilateral total trade flows between all countries using the Standard Trade International Classification (STIC revision 3), provided by the World Integrated Trade Solution (WITS) database. The data represents the total amount in US Dollars of import (export) from (to) one country to (from) another country. To quantify the intensity of the overall trade relationship between two countries we consider the measure proposed by Frankel \& Rose (1996) expressed as follows:

$$
w_{i j, t}=\frac{M_{i j, t}+X_{i j, t}}{G D P_{i, t}+G D P_{j, t}},
$$

where $G D P_{t}$ is the nominal gross domestic product (available in the WEO database) and $M_{i j, t}$ and $X_{i j, t}$ are respectively the bilateral total import and export. This measure captures the contribution of the bilateral trade to the wealth of the countries. To construct our interaction matrix, we average this measure over the period 2000-2007. ${ }^{19}$

We would have liked to consider an interaction matrix constructed from financialbased transmission channel, but we were not able to due to data constraints as most of the statistical data on bilateral financial transactions (e.g. portfolio investment data from IMF-CPIS database and cross-border banking statistics from the BIS database) are only available for a subset of the considered countries of our sample.

\section{Interaction matrices based on informational channels}

Information channels are based on investors' beliefs about countries' similarities. These beliefs are constructed from a wide range of macroeconomic and socioeconomic indicators. To characterise these information channels, we use annual macroeconomic data such as debt-to-GDP ratio and deficit-to-GDP ratio as it has been used in early work (Favero 2013). These variables are taken from the WEO database. We also consider the government stability index and the socioeconomic index as computed by ICRG database to account for institutional similarities. The government stability index captures both the government's ability to carry out its declared program, and its ability to stay in office. The socioeconomic index reflects the pressures at work in the society that could constrain government action. These two indexes have the particular feature that

\footnotetext{
${ }^{19}$ We also consider alternative intensity measures such as the share of the bilateral trade in the total trade of each country and obtained very similar results.
} 
they do not fluctuate through time. Based on these four types of country characteristics (two macroeconomic and two institutional), we measure countries' similarity as follows:

$$
w_{i j, t}^{l}=\frac{1}{\left|A_{i, t}^{l}-A_{j, t}^{l}\right|+1}, \quad l=1, \cdots, 4
$$

where $A_{i, t}^{l}$ refers to the value of the $l^{t h}$ characteristic in country $i$ at time $t$. Finally, we construct our four interaction matrices by averaging the similarity measure over the period 2000-2007. ${ }^{20}$

\section{Robustness analysis}

In this section, we assess the robustness of our main results when going beyond the transitional set of country-specific and system-wide global determinants to sovereign bond spreads. To this end, we control for common factors that could affect specific groups of countries (see Candelon et al. 2016). For the sake of simplicity, we only report the results based on the optimal convex combination of interaction matrices. As described below, we follow three separate strategies to re-estimate the model. First, in addition to the VIX, we control for financial market developments in both advanced and emerging countries by adding two auxiliary explanatory variables: the MSCI EAFE index and the MSCI emerging markets index. ${ }^{21}$ The results are summarized in the first column of Table C.3 (Model 1), where the optimal convex combination interaction matrix $\left(W^{*}\right)$ ) has been found to be identical to the one used in our main estimation. It can be seen that the spatial parameters $\rho$ and $\lambda$ remain significant, as well as all the variables that are found significant in our main findings.

In a second approach, we apply a statistical approach to quantify the regional common factors, using two alternative groupings. The first grouping splits advanced and emerging countries while the second gathers countries in 4 different pools, according to a clustering procedure presented below. The statistic procedure used consists in extracting the principal components (common factors) from sovereign spreads for each group of countries separately and adding these computed common factors as regressors to model (1) (see Candelon et al. 2016, for similar method). The considered threshold to retain principal components is such that their cumulative sum should explain at least

\footnotetext{
${ }^{20}$ We also use alternative measures to (24) such as the exponential of absolute distance between indicators, but the obtained results were left unchanged.

${ }^{21}$ The MSCI indices data come from Bloomberg.
} 
$90 \%$ of the total variance.

In the first scenario, we use the IMF classification and forms two groups: advanced and emerging countries. For the advanced countries group, one single component has been kept ( $P C 1 \_A d v$, explains $96 \%$ of the variance), while two are considered for the emerging countries group ( $P C 1_{-} E m$, explaining $87 \%$ of the variance and $P C 2 \_E m$ which contributes to another $5 \% \overline{)}$. ${ }^{22}$

Estimation results for this grouping of countries are presented in the second column of Table C.3 (Model 2) where the optimal convex combination matrix used is $W^{*}=$ $0.15 *$ Trade $+0.85 *$ Socio_eco . As for the first robustness check, parameters capturing the effect of dynamics in the sovereign risks remain significant, as well as the variables initially found significant in our main model.

In the second scenario, we take a more agnostic stance by clustering the countries according to similarity in the sovereign risks time-series behaviours. Specifically, we rely on the Dynamic Time Warping (DTW) algorithm with the Ward method to construct clusters of countries from their sovereign risk measures. ${ }^{23}$ Our procedure leads to the identification of four clusters, presented in Table C.1.

\section{Table C.1: Clusters of countries}

\begin{tabular}{ll}
\hline Cluster 1 & $\begin{array}{l}\text { Austria, Belgium, Finland, France, Germany, Netherlands, Denmark, Norway, Swe- } \\
\text { den, Switzerland, United Kingdom, Canada, Japan }\end{array}$ \\
\hline Cluster 2 & $\begin{array}{l}\text { Australia, Korea, Bulgaria, Poland, Turkey, Russia, China, Indonesia, Malaysia, } \\
\text { Philippines, Brazil, Chile, Colombia, Mexico, Peru, Uruguay, Tunisia, South Africa }\end{array}$ \\
\hline Cluster 3 & Greece, Argentina, Ukraine, Venezuela, Pakistan \\
\hline Cluster 4 & Ireland, Italy, Portugal, Spain, Hungary \\
\hline
\end{tabular}

As previously described, we next extract the principal components from the sovereign risk in each group and retain those that explain at least $90 \%$ of its total variance. Table C.2 reports the number of components retained for each group and their respective contribution to the variance of sovereign risk.

The last column of Table C.3 (Model 3) reports the results of this augmented model where the optimal convex combination interaction matrix is constructed as $W^{*}=0.25 *$ Trade $+0.75 *$ Socio_eco. We note that all parameters capturing the dynamics in the sovereign risk remain significant. Further, with the exception of the real interest rate

\footnotetext{
${ }^{22}$ We have also estimated the model using the second principal component extracted from advanced sovereign risk but its associated coefficient was not statistically significant.

${ }^{23}$ See Giorgino (2009) for more details about the DTW algorithm.
} 


\begin{tabular}{l|c} 
Component & $\begin{array}{c}\text { Contribution } \\
\text { to the variance }\end{array}$ \\
\hline PC1_clust1 & $57.74 \%$ \\
PC2_clust1 & $32.41 \%$ \\
\hline PC1_clust2 & $90.74 \%$ \\
\hline PC1_clust3 & $56.45 \%$ \\
PC2_clust3 & $40.22 \%$ \\
\hline PC1_clust4 & $90.91 \%$ \\
\hline
\end{tabular}

Table C.2: Principal Components for each cluster

variable, all determinants that were found statistically significant in our main model keep their significance. 
Table C.3: Estimation results with common factors by group of countries

\begin{tabular}{|c|c|c|c|}
\hline Variables & Model 1 & Model 2 & Model 3 \\
\hline$Y_{t-1}$ & $\begin{array}{c}0.877^{* * *} \\
(0.022)\end{array}$ & $\begin{array}{c}0.828^{* * *} \\
(0.022)\end{array}$ & $\begin{array}{c}0.722^{* * *} \\
(0.022)\end{array}$ \\
\hline$W Y_{t-1}$ & $\begin{array}{c}-0.536^{* * *} \\
(0.078)\end{array}$ & $\begin{array}{c}-0.837^{* * *} \\
(0.066)\end{array}$ & $\begin{array}{c}-0.693^{* * *} \\
(0.063)\end{array}$ \\
\hline$W Y_{t}$ & $\begin{array}{c}0.597^{* * *} \\
(0.061)\end{array}$ & $\begin{array}{c}0.365^{* * *} \\
(0.088)\end{array}$ & $\begin{array}{c}0.554^{* * *} \\
(0.060)\end{array}$ \\
\hline debt/GDP & $\begin{array}{c}0.018^{* * *} \\
(0.006)\end{array}$ & $\begin{array}{l}0.015^{* *} \\
(0.006)\end{array}$ & $\begin{array}{c}0.026^{* * *} \\
(0.006)\end{array}$ \\
\hline def/GDP & $\begin{array}{c}0.001 \\
(0.014)\end{array}$ & $\begin{array}{c}0.004 \\
(0.013)\end{array}$ & $\begin{array}{l}0.012 \\
(0.013)\end{array}$ \\
\hline current/GDP & $\begin{array}{l}-0.014 \\
(0.017)\end{array}$ & $\begin{array}{l}-0.019 \\
(0.017)\end{array}$ & $\begin{array}{l}-0.008 \\
(0.016)\end{array}$ \\
\hline inflation & $\begin{array}{c}0.170^{* * *} \\
(0.050)\end{array}$ & $\begin{array}{c}0.131^{* * *} \\
(0.051)\end{array}$ & $\begin{array}{c}0.194^{* * *} \\
(0.048)\end{array}$ \\
\hline GDP growth & $\begin{array}{c}-0.006 \\
(0.042)\end{array}$ & $\begin{array}{l}-0.020 \\
(0.041)\end{array}$ & $\begin{array}{c}-0.055 \\
(0.039)\end{array}$ \\
\hline VIX & $\begin{array}{c}0.024^{* * *} \\
(0.006)\end{array}$ & $\begin{array}{c}0.020^{* * *} \\
(0.007)\end{array}$ & $\begin{array}{c}0.016^{* * *} \\
(0.007)\end{array}$ \\
\hline Reer & $\begin{array}{l}0.014^{* *} \\
(0.007)\end{array}$ & $\begin{array}{l}0.014^{*} \\
(0.007)\end{array}$ & $\begin{array}{l}-0.009 \\
(0.008)\end{array}$ \\
\hline MSCI_EAFE & $\begin{array}{c}0.013^{* * *} \\
(0.005)\end{array}$ & & \\
\hline MSCI_Em & $\begin{array}{c}-0.027^{* * *} \\
(0.005)\end{array}$ & & \\
\hline $\mathrm{PC} 1 \_\mathrm{Adv}$ & & $\begin{array}{c}0.034^{* * *} \\
(0.008)\end{array}$ & \\
\hline PC1_Em & & $\begin{array}{c}0.076^{* * *} \\
(0.010)\end{array}$ & \\
\hline PC2_Em & & $\begin{array}{c}0.090^{* * * *} \\
(0.036)\end{array}$ & \\
\hline PC1_clust1 & & & $\begin{array}{c}0.029 \\
(0.078)\end{array}$ \\
\hline PC2_clust1 & & & $\begin{array}{c}0.039 \\
(0.108)\end{array}$ \\
\hline PC1_clust2 & & & $\begin{array}{l}0.039^{*} \\
(0.022)\end{array}$ \\
\hline PC1_clust3 & & & $\begin{array}{c}0.060^{* * *} \\
(0.012)\end{array}$ \\
\hline PC2_clust3 & & & $\begin{array}{c}0.190^{* * *} \\
(0.017)\end{array}$ \\
\hline PC1_clust4 & & & $\begin{array}{l}0.063^{* *} \\
(0.030)\end{array}$ \\
\hline $\log \mathrm{L}$ & -1221.830 & -1210.273 & -1154.833 \\
\hline
\end{tabular}

Notes: ${ }^{* *}$ and ${ }^{* * *}$ denote significance at the $5 \%$ and $1 \%$ respectively. Standard deviations are in parentheses. 